\title{
Data Requirements and Modeling for Gas Hydrate-Related Mixtures and a Comparison
} of Two Association Models

\section{Liang, Xiaodong; Aloupis, Georgios; Kontogeorgis, Georgios M.}

Published in:

Journal of Chemical and Engineering Data

Link to article, DOI:

10.1021/acs.jced.7b00081

Publication date:

2017

Document Version

Peer reviewed version

Link back to DTU Orbit

Citation (APA):

Liang, X., Aloupis, G., \& Kontogeorgis, G. M. (2017). Data Requirements and Modeling for Gas Hydrate-Related Mixtures and a Comparison of Two Association Models. Journal of Chemical and Engineering Data, 62(9), 25922605. https://doi.org/10.1021/acs.jced.7b00081

\section{General rights}

Copyright and moral rights for the publications made accessible in the public portal are retained by the authors and/or other copyright owners and it is a condition of accessing publications that users recognise and abide by the legal requirements associated with these rights.

- Users may download and print one copy of any publication from the public portal for the purpose of private study or research.

- You may not further distribute the material or use it for any profit-making activity or commercial gain

- You may freely distribute the URL identifying the publication in the public portal 


\title{
Data requirements and modeling for gas hydrate related mixtures and a comparison of two association models
}

\author{
Xiaodong Liang, Georgios Aloupis, Georgios M. Kontogeorgis* \\ Center for Energy Resources Engineering (CERE), \\ Department of Chemical and Biochemical Engineering, \\ Technical University of Denmark, 2800 Kgs. Lyngby, Denmark
}

Email: gk@kt.dtu.dk 


\begin{abstract}
The association theory based advanced thermodynamic models gain more and more attention and applications in many industries. The Cubic Plus Association (CPA) and the simplified Perturbed-Chain Statistical Associating Fluid Theory (sPC-SAFT) equations of state (EOS) are two of the most widely used association models in the chemical and petroleum industries. The CPA model is extensively used in flow assurance, in which gas hydrate is one of the central topics. Experimental data play a vital role in validating models and obtaining model parameters. In this work, we will compare the performance of the CPA and sPC-SAFT EOS for modeling the fluid phase equilibria of gas hydrate related systems, and try to explore how the models can help in suggesting experimental measurements. These systems contain water, hydrocarbon (alkane or aromatic) and either methanol or mono-ethylene glycol. It is well-known that the determination of SAFT-type model parameters for associating fluids remains a challenge, since there are at least five pure component parameters for these compounds, and there is no property combination found yet to be enough to ensure the best parameter set. Therefore, in this work two parameter sets have been chosen for the sPC-SAFT EOS for a fair comparison. The comparisons are made for pure fluid properties, vapor-liquid equilibria and liquid-liquid equilibria of binary and ternary mixtures, as well as vapor-liquid-liquid equilibria of quaternary mixtures. The results show, from an overall point of view, that these two models have equally good performance, and the two parameter sets with the sPC-SAFT EOS are also comparable, especially for the vapor-liquid equilibria systems. Moreover, the modeling results suggest that some data are less reliable than others, which indicates the need for more measurements to further validate the models, especially for multicomponent systems.
\end{abstract}

Keywords: Gas hydrate, inhibitor, CPA, sPC-SAFT, Vapor-liquid-liquid equilibria 


\section{Introduction}

Fair comparisons of thermodynamic models are rare in literature. When comparisons are only done for the correlative performance, e.g. binary phase equilibria, differences can be masked by the adjustable parameters which often play an important role. This is the case even when classical thermodynamic models like cubic equations of state (EOS) are compared against modern Statistical Associating Fluid Theory (SAFT)-type or similar EOS. Thus, the true value of thermodynamic models should be based on predictive calculations, e.g. multicomponent phase equilibria or prediction of properties other than those used in the parameter estimation, both of which are also important for engineering applications. In this work we focus on the multicomponent multiphase equilibria of systems of relevance to the petroleum industry (water-alcohols/glycols-hydrocarbons). While such multicomponent systems are of great importance, not many data are available, possibly due to the experimental difficulties, e.g. the detection of low solubilities in some of the phases. The corresponding author recalls a communication with Kenneth Marsh some years ago discussing a manuscript published in Journal of Chemical \& Engineering Data. That manuscript contained experimental data for many water-glycol-hydrocarbon systems, but unfortunately they were not accurate. The corresponding author appreciated Kenneth Marsh's interference in this case and with his continuous effort the authors repeated some of the measurements and today we have some of the best water-monoethylene glycol (MEG)-alkane LLE data available in the literature. ${ }^{1}$ This is highly appreciated as such data are extremely rare and only very few laboratories can measure them.

This work focuses on the fluid phase equilibria of gas hydrate related systems. A combination of appropriate temperature and pressure conditions as well as the presence of light gases may lead water molecules to reform into coplanar poly-membered ( 5 or 6 ) rings and create a 3D polyhedral shaped formations with the light gases trapped within it. In this way, the water acts like a cage. This 
phenomenon is called gas hydrate formation, which is considered as one of the major concerns in production, transportation and processing in the petroleum industry. This is because, when it occurs, it can reduce the flow of the gas in the pipeline and eventually block the pipeline stopping the production, and it might also affect and damage the equipment. ${ }^{2}$ Addition of chemicals like alcohols and glycols, called thermodynamic gas hydrate inhibitors, is one widely used technique to prevent gas hydrate formation in the oil and gas industry. Methanol and MEG are common choices, while ethanol is an alternative. Methanol and MEG are both effective and reliable in preventing gas hydrate formation. MEG gains more attention nowadays, because it can be reused and regenerated with insignificant losses, and decreases the possibility of creation and occurrence of corrosion in the pipelines. ${ }^{3}$

Thermodynamic models play a vital role in determining the minimum necessary amount of chemicals used as gas hydrate inhibitors. The Cubic Plus Association (CPA) EOS ${ }^{4}$ has been shown to be very useful in predicting gas hydrate formation, based on extensive validations for many gas hydrate related systems. ${ }^{5-7}$ The CPA EOS uses the same association term of the SAFT models, ${ }^{8-13}$ and one of the most widely used SAFT models, the Perturbed Chain-SAFT (PC-SAFT) EOS ${ }^{14,15}$ and its simplified version (sPC-SAFT), ${ }^{16}$ has gained more and more attention in the petroleum and chemical industries. ${ }^{5}$ Therefore, a systematic investigation on the performance of the sPC-SAFT EOS in modeling the fluid phase equilibria of gas hydrate related systems might further contribute to the acceptance of this model in the petroleum industry, and it might provide an alternative to cubic EOS for engineers. Moreover, a thorough and fair comparison is believed necessary to conclude which model or modeling approach may be better, and it will also help in giving more confidence of existing and/or suggesting more experimental measurements, when necessary. 
Many works have been done in modeling systems containing hydrocarbon, water, methanol or MEG with the association theory based models. ${ }^{17-22}$ However, only few comparisons among these models have been published for multicomponent multiphase equilibria, and one of the most recent studies was for water-methanol-hydrocarbons with the CPA and SPC-SAFT EOS. ${ }^{23}$ This work will focus on a fair comparison of these two models on their performance in modeling gas hydrate related systems in both correlation and prediction manners. The rest of the work is organized as (1) brief introduction of the two models in section 2; (2) presentation of the experimental data in section 3; (3) modeling results and discussion in section 4 and (4) conclusion and suggestions in section 5.

\section{Models}

In the past three decades, the association theory based thermodynamic models have been gaining attention and applications in many areas, including oil \& gas, chemicals, environments and pharmaceuticals. The CPA and SPC-SAFT EOS are, among the association models, two of the most widely used models in the chemical and petroleum industries. ${ }^{5}$

\subsection{CPA EOS}

The CPA EOS was proposed by Kontogeorgis et al. ${ }^{4}$ and it is a combination of the SRK (or other cubic) EOS, widely used in the petroleum industry, and the association term of the SAFT type models. The CPA reduces to SRK in the absence of hydrogen bonding compounds, leading to a good balance between accuracy and simplicity, thus it helps in gaining easy acceptance in the oil, gas and chemical industries. In terms of pressure, the CPA EOS can be expressed for mixtures as:

$$
P=\frac{R T}{V_{m}-b}-\frac{a(T)}{V_{m}\left(V_{m}+b\right)}-\frac{1}{2} \frac{R T}{V_{m}}\left(1+\rho \frac{\partial \ln g}{\partial \rho}\right) \sum_{i} x_{i} \sum_{A_{i}}\left(1-X^{A_{i}}\right)
$$

where $\rho$ is the molar density $\left(\rho=1 / V_{m}\right)$. 


\subsection{SPC-SAFT EOS}

The PC-SAFT EOS was developed by Gross and Sadowski. ${ }^{14}$ In terms of the reduced residual Helmholtz free energy, it can be expressed as:

$$
a^{r}=\left(a^{h s}+a^{\text {chain }}\right)+a^{\text {disp }}+a^{a s s o c}
$$

where $a^{h s}$ and $a^{\text {chain }}$ are the contributions of the hard sphere segment-segment interaction and the chain formation, respectively. The dispersion force $a^{\text {disp }}$ is built by extending the perturbation theory of Barker and Henderson ${ }^{24}$ to use the hard-chain as the reference term. The term $a^{a s s o c}$ represents the contributions of association forces of sites, which can be expressed as:

$$
a^{a s s o c}=\sum_{i} x_{i}\left[\sum_{A_{i}}\left(\ln X^{A_{i}}-\frac{X^{A_{i}}}{2}\right)+\frac{M_{i}}{2}\right]
$$

where $M_{i}$ is the association site number of molecule $i$, and $X^{A_{i}}$ is the fraction of molecules $i$ not bonded at site $\mathrm{A}$, given by:

$$
X^{A_{i}}=\left[1+\sum_{j} \sum_{B_{j}} \rho_{j} X^{B_{j}} \Delta^{A_{i} B_{j}}\right]^{-1}
$$

where $\Delta^{A_{i} B_{j}}$ is the association strength between the site $A_{i}$ and site $B_{j}$, which is obtained as:

$$
\Delta^{A_{i} B_{j}}=N_{a v} \sigma_{i j}^{3} g^{h s} \kappa^{A_{i} B_{j}}\left[\exp \left(\frac{\varepsilon^{A_{i} B_{j}}}{k T}\right)-1\right]
$$

In this work, the sPC-SAFT EOS proposed by von Solms et al. ${ }^{16}$ with both modifications is used. It simplifies the original PC-SAFT EOS and reduces the computational time, without loss of accuracy for many applications. The same pure component parameters can be used for both the original and simplified PC-SAFT EOS. The readers are referred to the literature ${ }^{5,14,16}$ for more details on equations and symbols. It is relevant to mention the combining rule of the association volume, which will be used 
in some cases in the following discussion. For a binary system consisting of two associating compounds, e.g. water and methanol, the following combining rule is used

$$
\left(\sigma_{i j}^{3} \kappa^{A_{i} B_{j}}\right)=\sqrt{\left(\sigma_{i i}^{3} \kappa^{A_{i} B_{i}}\right)\left(\sigma_{j j}^{3} \kappa^{A_{j} B_{j}}\right)}
$$

Between an associating compound and an aromatic one, e.g. water-benzene, however, the following combining rule is used

$$
\left(\sigma_{i j}^{3} \kappa^{A_{i} B_{j}}\right)=\kappa^{\text {cross }}\left(\frac{\sigma_{i i}^{3}+\sigma_{j j}^{3}}{2}\right)
$$

This combing rule is volume based, not the one commonly used for the diameters. It is inspired by the CPA EOS, in which the term $\sigma_{i i}^{3}$ is replaced by the co-volume parameter b. However, people may expected that similar results are obtained after fitting the cross association volume to the experimental data. More details of the models, equations and symbols are referred to the literature. ${ }^{4,5,14}$

\section{Experimental data}

In this work, we focus on the relationship among experimental data, models and modeling approaches, instead of providing a complete literature review on all pertinent experimental data. Therefore, we selected the mixtures of water, methanol or MEG and hydrocarbon(s), as the performances of the models for these systems (water-gas hydrate inhibitors-oil) may be crucial in determining their acceptance by the petroleum industry. When the pure compound model parameters are available, the phase equilibrium data of binary mixtures are helpful in the models' correlative performance and testing the predictive capabilities of these pure component parameters, as well as in determining the binary interaction parameters which will be used in the next step for predictions of multicomponent systems. The collected data of binary and multicomponent mixtures of relevance to this study are listed in Table 1 and 2, respectively. Not all of these data are going to be used in the 
modeling part, but they are useful in the discussion and in future studies. Some of the references contain data collections and recommendations, which may be useful as well.

Table 1. Experimental data review of binary mixtures of relevance to this study (polar compounds like water, alcohols and MEG with hydrocarbons and cross-associating systems of the polar compounds)

\begin{tabular}{ccccc}
\hline $1^{\text {st }}$ comp. & $2^{\text {nd }}$ comp. & T range $(\mathrm{K})$ & P range (bar) & Ref. \\
\hline Methane & Water & $274.19-483.15$ & $0.07-1334$ & $25-32$ \\
Methane & Methanol & $200.0-502.2$ & $6.9-2935$ & $25,32-35$ \\
Methane & Ethanol & $298.15-498.15$ & $5.0-364.2$ & $36-38$ \\
Methane & MEG & $283.2-398.15$ & $1.1-396.2$ & $32,39,40$ \\
Ethane & Water & $274.26-373.15$ & $3.2-49.5$ & $28,32,41,42-44$ \\
Ethane & Methanol & $283.2-303.2$ & $5-67.7$ & 32,45 \\
Ethane & Ethanol & $298.15-498.15$ & $2.5-117.7$ & 36,38 \\
Ethane & MEG & $283.2-303.2$ & $5-40$ & 32 \\
n-Hexane & Water & $270.0-490.0$ & $3.4-29.6$ & 46,47 \\
n-Hexane & Methanol & $245.15-339.60$ & $0.1-1500$ & $48-54$ \\
n-Hexane & Ethanol & $328.15-351.45$ & $0.5-1.0$ & 55,56 \\
n-Hexane & MEG & $307.95-330.35$ & 1.0 & 57 \\
n-Octane & Water & $310.9-539.1$ & $0.1-784.5$ & 58,59 \\
n-Octane & Methanol & $288.91-372.3$ & $0.1-1500$ & $60-62$ \\
n-Octane & Ethanol & $313.15-348.15$ & $0.04-0.95$ & 63,64 \\
Benzene & Water & $279.15-453.15$ & $0.06-20.2$ & 65,66 \\
Benzene & Methanol & $298.15-363.15$ & $0.1-3.1$ & $67-72$ \\
Benzene & Ethanol & $293.15-353.26$ & $0.06-1.0$ & $56,65,73-76$ \\
Benzene & MEG & $279.2-342.1$ & 1.0 & 77 \\
Toluene & Water & $273.15-458.15$ & $0.02-17.0$ & 66 \\
Toluene & Methanol & 313.15 & $0.08-0.37$ & 76 \\
Toluene & Ethanol & $308.15-328.15$ & $0.06-0.41$ & 78,79 \\
Toluene & MEG & $279.1-361.0$ & 1.0 & 77 \\
Water & Methanol & $298.15-523.15$ & $0.04-85.1$ & $80-83$ \\
Water & MEG & $343.15-363.15$ & $0.06-0.7$ & 84 \\
\hline
\end{tabular}


Table 2. Experimental data review of multicomponent mixtures of type water-alcohol/MEG/TEGhydrocarbons and methanol/MEG-hydrocarbons.

\begin{tabular}{|c|c|c|c|c|c|c|}
\hline $1^{\text {st }}$ comp. & $2^{\text {nd }}$ comp. & $3^{\text {rd }}$ comp. & $4^{\text {th }}$ comp. & T range $(\mathrm{K})$ & $\mathrm{P}$ range (bar) & Ref. \\
\hline Water & Methanol & Methane & & $267.55-313.45$ & $42-400.5$ & $25,28,85$ \\
\hline Water & Methanol & Ethane & & 283.2-303.2 & $5-40$ & 28 \\
\hline Water & Methanol & Propane & & $269.35-293.15$ & $2.3-63.2$ & 85,86 \\
\hline Water & Methanol & n-Butane & & $273.15-293.15$ & 1.0 & 85 \\
\hline Water & Methanol & Hexane & & $293.2-323.15$ & 1.0 & $87-89$ \\
\hline Water & Methanol & Heptane & & 298.2 & 1.0 & 90 \\
\hline Water & Methanol & Benzene & & $293.15-333.15$ & 1.0 & 87,91 \\
\hline Water & Methanol & Toluene & & 303.15 & 1.0 & 92 \\
\hline Water & MEG & Methane & & $283.2-303.2$ & $50-400.6$ & 28 \\
\hline Water & MEG & Ethane & & $283.2-303.2$ & $5-40$ & 28 \\
\hline Water & MEG & Hexane & & $283.15-323.15$ & 1.0 & 1,93 \\
\hline Water & MEG & Nonane & & 313.15 & 1.0 & 94 \\
\hline Water & MEG & Benzene & & $298.2-323.2$ & 1.0 & 77 \\
\hline Water & MEG & Toluene & & 298.2-323.2 & 1.0 & 77 \\
\hline Water & MEG & Ethylbenzene & & 313.15 & 1.0 & 94 \\
\hline Water & Ethanol & Propane & & $313-403$ & 99.05 & 95 \\
\hline Water & Ethanol & Hexane & & $329.26-349.66$ & 1.0 & 96 \\
\hline Water & Ethanol & Heptane & & 298.2 & 1.0 & 90 \\
\hline Water & Ethanol & Benzene & & $293.15-328.15$ & 1.0 & 97,98 \\
\hline Water & Ethanol & Toluene & & 303.15 & 1.0 & 92 \\
\hline Water & TEG & Toluene & & $368.75-412.55$ & 0.85 & 77,99 \\
\hline Methanol & Methane & Ethane & & 275.2-283.2 & $50-400$ & 28 \\
\hline Methanol & Benzene & Heptane & & 298.15 & 1.0 & 61 \\
\hline Methanol & Benzene & Octane & & 298.15 & 1.0 & 61 \\
\hline Methanol & Benzene & Nonane & & 298.15 & 1.0 & 61 \\
\hline Methanol & Benzene & Decane & & 298.15 & 1.0 & 61 \\
\hline Methanol & Toluene & Heptane & & 298.15 & 1.0 & 61 \\
\hline Methanol & Toluene & Octane & & 298.15 & 1.0 & 61 \\
\hline Methanol & Toluene & Nonane & & 298.15 & 1.0 & 61 \\
\hline Methanol & Toluene & Decane & & 298.15 & 1.0 & 61 \\
\hline MEG & Methane & Ethane & & $275.2-283.2$ & $49.9-400$ & 28 \\
\hline Water & Methanol & Methane & Ethane & $275.2-283.2$ & $13-400$ & 28 \\
\hline Water & Methanol & Methane & Propane & $281.37-310.93$ & $34.47-208.77$ & 100 \\
\hline Water & Methanol & Methane & Heptane & $263.15-323.15$ & $69.02-70.74$ & 101 \\
\hline Water & Methanol & Methane & Toluene & $263.15-323.15$ & $80.05-96.11$ & 101 \\
\hline Water & MEG & Methane & Ethane & 275.2-283.2 & $5-400$ & 28 \\
\hline Water & MEG & Methane & Propane & $273.15-283.15$ & $69.02-70.39$ & 102 \\
\hline Water & MEG & Methane & Hexane & $263.15-283.15$ & 68.95-69.02 & 102 \\
\hline Water & MEG & Methane & Octane & 281.1-363.2 & $31-150$ & 103 \\
\hline Water & MEG & Methane & Toluene & $263.15-323.15$ & $69.22-69.5$ & 101 \\
\hline
\end{tabular}




\section{Modeling results and discussion}

\subsection{Pure component parameters}

The first step in modeling fluid phase equilibria using EOS is to obtain the pure component parameters. The CPA and SPC-SAFT EOS have the same number of pure component parameters, i.e. three and five parameters for non-associating and associating fluids, respectively. In general, these parameters are obtained by fitting to vapor pressure and liquid density. It is well-known that the determination of SAFT parameters for associating fluids is a challenge, since there are at least five pure component parameters for these compounds, and there is no property combination found yet to be enough to ensure the best parameter set. ${ }^{104-106}$ Several parameter sets have been published for water, methanol and $\mathrm{MEG}^{107}$ with the sPC-SAFT EOS. Two of these sets, while having rather different parameter values, provide equally good representation of vapor pressures and liquid densities, have been chosen for the sPC-SAFT EOS for a fair comparison. Based on our experience, the two-site association scheme $2 \mathrm{~B}^{108}$ is used for methanol in this work, while more sophisticated developments may be needed for the cross association for alcohol containing mixtures. ${ }^{109}$ The pure component parameters are given in Tables 3 and 4 for the CPA and SPC-SAFT EOS, respectively.

Firstly, these parameters of the associating fluids are validated against the vapor pressure and liquid density data from the DIPPR ${ }^{110}$ and NIST ${ }^{111,112}$ databases in Table 5. The percentage average absolute deviations (\%AAD), defined in the following equation

$$
\% \operatorname{AAD}(\Omega)=\frac{1}{N p} \sum_{i=1}^{N p}\left|\frac{\Omega^{c a l}}{\Omega^{e x p}}-1\right| \times 100 \%
$$

where $\Omega$ is vapor pressure, liquid density or solubility used in the following sections. $N p$ is the number of experimental data points. 
In addition, an average \%AAD is defined for each model and each phase

$$
\text { average } \% \mathrm{AAD}=\frac{\sum \% \mathrm{AAD}}{\text { Number of } \% \mathrm{AAD}}
$$

The vapor pressures of water from the CPA and sPC-SAFT EOS are also plotted in Figure 1. It can be seen from Table 5 and Figure 1 that these two models and the two parameter sets of the sPC-SAFT EOS have quite similar performance, and in general the data from the two databases are consistent with each other.

Table 3. The CPA parameters of relevant compounds

\begin{tabular}{cccccccc}
\hline \multirow{2}{*}{ Comp. } & $b$ & $\Gamma=a_{0} / R b$ & $c_{1}$ & $\varepsilon^{A_{i} B_{i}} / k$ & $\kappa^{A_{i} B_{i}}$ & Scheme & \multirow{2}{*}{ Ref. } \\
\cline { 2 - 6 } & $(\mathrm{L} / \mathrm{mol})$ & $(\mathrm{K})$ & $(-)$ & $(\mathrm{K})$ & $(-)$ & $(-)$ & \\
\hline Methane & 0.0291 & 959.028 & 0.44718 & - & - & - & 113 \\
Ethane & 0.04288 & 1544.55 & 0.58463 & - & - & - & 113 \\
n-Hexane & 0.10789 & 2640.03 & 0.8313 & - & - & - & 114 \\
Benzene & 0.07499 & 2867.19 & 0.7576 & - & - & - & 115 \\
Toluene & 0.09214 & 3051.36 & 0.8037 & - & - & - & 115 \\
Methanol & 0.030978 & 1573.71 & 0.43102 & 2957.78 & 16.1 & $2 \mathrm{~B}$ & 114 \\
MEG & 0.0514 & 2531.71 & 0.6744 & 2375.75 & 14.1 & $4 \mathrm{C}$ & 116 \\
Water & 0.014515 & 1017.34 & 0.67359 & 2003.25 & 69.2 & $4 \mathrm{C}$ & 114 \\
\hline
\end{tabular}

Table 4. The sPC-SAFT parameters of relevant compounds

\begin{tabular}{cccccccc}
\hline \multirow{2}{*}{ Comp. } & $\mathrm{m}$ & $\sigma$ & $\varepsilon / k$ & $\varepsilon^{A_{i} B_{i}} / k$ & $\kappa^{A_{i} B_{i}}$ & Scheme & \multirow{2}{*}{ Ref. } \\
\cline { 2 - 6 } & $(-)$ & $(\AA)$ & $(\mathrm{K})$ & $(\mathrm{K})$ & $(-)$ & $(-)$ & \\
\hline Methane & 1.0 & 3.7039 & 150.03 & - & - & - & 14 \\
Ethane & 1.6069 & 3.5206 & 191.42 & - & - & - & 14 \\
n-Hexane & 3.0576 & 3.7983 & 236.77 & - & - & - & 14 \\
Benzene & 2.4653 & 3.6478 & 287.35 & - & - & - & 14 \\
Toluene & 2.8149 & 3.7169 & 285.69 & - & - & - & 14 \\
Methanol (\#1) & 1.5255 & 3.23 & 188.9 & 2899.50 & 0.035176 & $2 \mathrm{~B}$ & 15 \\
Methanol (\#2) & 1.8824 & 3.002 & 181.77 & 2738.03 & 0.0547 & $2 \mathrm{~B}$ & 117 \\
MEG (\#1) & 1.90878 & 3.5914 & 325.23 & 2080.03 & 0.0235 & $4 \mathrm{C}$ & 118 \\
MEG (\#2) & 2.3535 & 3.3186 & 280.29 & 2006.60 & 0.04539 & $4 \mathrm{C}$ & 119 \\
Water (\#1) & 1.5 & 2.6273 & 180.3 & 1804.22 & 0.18 & $4 \mathrm{C}$ & 120 \\
Water (\#2) & 2.0 & 2.3449 & 171.67 & 1704.06 & 0.1596 & $4 \mathrm{C}$ & 106 \\
\hline
\end{tabular}


Table 5. \%AAD of vapor pressure and liquid density against the data from DIPPR and NIST*

\begin{tabular}{cccccccc}
\hline \multirow{3}{*}{ Comp. } & \multirow{2}{*}{$\begin{array}{c}\text { Tr } \\
\text { range }\end{array}$} & \multirow{2}{*}{ CPA } & $\begin{array}{c}\text { SPC-SAFT } \\
(\# 1)\end{array}$ & $\begin{array}{c}\text { sPC-SAFT } \\
(\# 2)\end{array}$ & \multirow{2}{*}{ CPA } & $\begin{array}{c}\text { sPC-SAFT } \\
(\# 1)\end{array}$ & $\begin{array}{c}\text { sPC-SAFT } \\
(\# 2)\end{array}$ \\
\hline Water & $0.5-0.95$ & $0.72(0.73)$ & $0.87(0.96)$ & $1.39(1.48)$ & $1.19(1.10)$ & $3.40(3.36)$ & $2.20(2.12)$ \\
Methanol & $0.5-0.95$ & $1.18(0.75)$ & $1.72(1.60)$ & $1.32(1.23)$ & $0.53(0.61)$ & $0.65(0.73)$ & $0.36(0.50)$ \\
MEG & $0.5-0.65$ & $1.45(1.65)$ & $0.35(0.58)$ & $1.28(1.07)$ & $0.65(-)$ & $1.76(-)$ & $1.76(-)$ \\
\hline *
\end{tabular}

${ }^{*}$ The values inside the parentheses is the \%AAD calculated based on the data from NIST. ${ }^{11}$

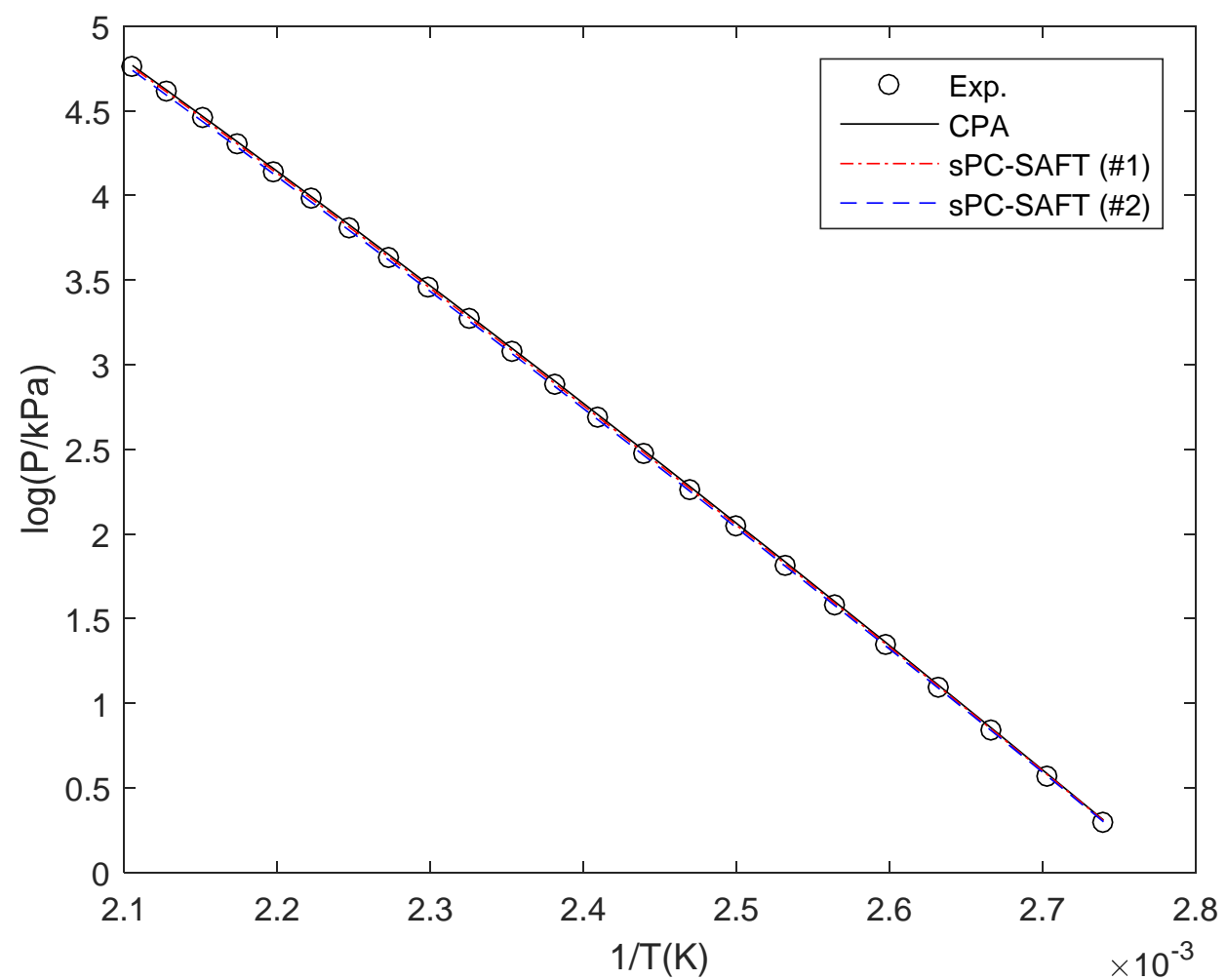

Figure 1. Vapor pressure of water versus temperature $(1 / \mathrm{T})$ from the CPA and SPC-SAFT EOS. The experimental data are from NIST. ${ }^{111}$

\subsection{Binary Vapor-Liquid Equilibria (VLE)}

The modeling results of selected binary mixtures are presented in Table 6 . The prediction result of each system is given inside parentheses after the correction one, which needs the binary interaction parameter $k_{i j}$. The average \%AADs of each model are also given in the last row of the table for the correlation results. It can be concluded that the three models show quite similar performance in 
correlating data, even though they predict different results in some cases. It is interesting to notice that negative values of $k_{i j}$ are needed for both models to correlate the systems of water-methanol/MEG.

Table 6. Binary interaction parameters and both the correlated and predicted \%AAD Pressure*

\begin{tabular}{|c|c|c|c|c|c|c|c|c|}
\hline \multirow{3}{*}{$\begin{array}{l}\mathrm{Np} \\
287\end{array}$} & \multirow{3}{*}{$\begin{array}{c}\mathrm{T}(\mathrm{K}) \\
274.19- \\
444.26\end{array}$} & \multirow{3}{*}{$\begin{array}{c}\text { System } \\
\text { Methane } \\
\text { Water }\end{array}$} & \multicolumn{6}{|c|}{$\mathrm{k}_{\mathrm{ij}} / \mathrm{K}^{\text {cross }} \& \% \mathrm{AAD}$ Pressure } \\
\hline & & & \multicolumn{2}{|c|}{ CPA } & \multicolumn{2}{|c|}{ sPC-SAFT (\#1) } & \multicolumn{2}{|c|}{ sPC-SAFT (\#2) } \\
\hline & & & $\begin{array}{c}0.7988 \\
-236.5 / T\end{array}$ & $6.3(42)$ & $\begin{array}{c}0.2967 \\
-89.61 / T\end{array}$ & 11(37) & $\begin{array}{c}0.2306 \\
-92.62 / T\end{array}$ & $9.3(>100)$ \\
\hline 165 & $\begin{array}{c}274.19- \\
344.26\end{array}$ & $\begin{array}{l}\text { Methane } \\
\text { Water }\end{array}$ & $\begin{array}{c}0.7988 \\
-236.5 / T \\
\end{array}$ & $7.0(33)$ & $\begin{array}{c}0.3768 \\
-114.0 / T \\
\end{array}$ & $5.6(30)$ & $\begin{array}{c}0.2846 \\
-109.2 / T \\
\end{array}$ & $6.0(>100)$ \\
\hline 97 & $\begin{array}{c}220.00- \\
338.20\end{array}$ & $\begin{array}{l}\text { Methane } \\
\text { Methanol }\end{array}$ & 0.053 & $12(27)$ & 0.041 & $8.0(39)$ & 0.01 & 11(19) \\
\hline 85 & $\begin{array}{l}298.15- \\
398.15\end{array}$ & $\begin{array}{l}\text { Methane } \\
\text { MEG }\end{array}$ & 0.18 & $8.0(56)$ & 0.070 & $5.4(49)$ & 0.064 & $7.2(47)$ \\
\hline 153 & $\begin{array}{c}274.26- \\
444.26\end{array}$ & $\begin{array}{l}\text { Ethane } \\
\text { Water }\end{array}$ & $\begin{array}{c}0.5437 \\
-143.3 / T \\
\end{array}$ & $27(64)$ & $\begin{array}{c}0.2224 \\
-52.42 / T \\
\end{array}$ & $27(75)$ & $\begin{array}{c}0.1773 \\
-53.97 / T \\
\end{array}$ & $27(55)$ \\
\hline 33 & $\begin{array}{l}283.2- \\
303.20 \\
\end{array}$ & $\begin{array}{c}\text { Ethane } \\
\text { Methanol }\end{array}$ & 0.028 & $6.1(16)$ & 0.031 & $6.1(24)$ & 0.020 & $5.9(19)$ \\
\hline 162 & $\begin{array}{l}293.15- \\
333.15\end{array}$ & $\begin{array}{l}\text { Hexane } \\
\text { Methanol }\end{array}$ & 0.01 & $4.3(6.4)$ & 0.027 & $4.9(12)$ & 0.021 & $4.4(11)$ \\
\hline 128 & $\begin{array}{c}298.15- \\
363.15\end{array}$ & $\begin{array}{l}\text { Benzene } \\
\text { Methanol }\end{array}$ & 0.0068 & $3.2(3.7)$ & 0.0093 & $5.9(6.6)$ & 0.011 & $5.2(6.3)$ \\
\hline 128 & $\begin{array}{c}298.15- \\
363.15\end{array}$ & $\begin{array}{l}\text { Benzene } \\
\text { Methanol }\end{array}$ & $0.02 / 0.01$ & $1.9(3.7)$ & $0.045 / 0.11$ & $1.4(6.6)$ & $0.04 / 0.11$ & $1.3(6.3)$ \\
\hline 78 & $\begin{array}{l}313.15- \\
318.15\end{array}$ & $\begin{array}{l}\text { Toluene } \\
\text { Methanol }\end{array}$ & -0.01 & $9(10)$ & -0.0067 & $15(15)$ & -0.0013 & $13(13)$ \\
\hline 78 & $\begin{array}{l}313.15- \\
318.15 \\
\end{array}$ & $\begin{array}{c}\text { Toluene } \\
\text { Methanol }\end{array}$ & $0.034 / 0.029$ & $3.3(10)$ & $0.045 / 0.13$ & $3.0(15)$ & $0.040 / 0.13$ & $3.0(13)$ \\
\hline 130 & $\begin{array}{c}298.05- \\
523.15\end{array}$ & $\begin{array}{c}\text { Water } \\
\text { Methanol }\end{array}$ & -0.09 & $2.7(13)$ & -0.059 & $2.8(14)$ & -0.066 & $2.5(19)$ \\
\hline 40 & $\begin{array}{l}343.15- \\
363.15 \\
\end{array}$ & $\begin{array}{l}\text { Water } \\
\text { MEG }\end{array}$ & -0.115 & $2.8(26)$ & -0.05 & $2.5(20)$ & -0.057 & $3.5(27)$ \\
\hline & $\begin{array}{l}\text { average } 0 \\
\text { nly for co }\end{array}$ & $\begin{array}{l}\mathrm{AD} \\
\text { lation) }\end{array}$ & & 7.2 & & 7.6 & & 7.6 \\
\hline
\end{tabular}

${ }^{*}$ The value inside the parenthesis is from prediction, i.e. $k_{i j}=0$ and $\kappa^{\mathrm{cross}}=0 ; \mathrm{Np}$ is number of data point. 
Figure 2 presents the correlated results of the solubility of methane in water using CPA and sPCSAFT EOS, which clearly shows similar performance from these models. Since the gas hydrate formation usually occurs below $310 \mathrm{~K}$, we developed also a temperature dependent $k_{i j}$ by correlating the data below $350 \mathrm{~K}$ only. These two $k_{i j}$ sets are compared in Figure 3, together with a constant $k_{i j}$, which are calculated from the correlations in the first row of Table 6 at temperature $313.45 \mathrm{~K}$. It can be seen from Figure 3 that a temperature dependent $k_{i j}$ is necessary for this binary mixture, while the two temperature dependencies show similar performance. We have previously observed that a temperature independent $k_{i j}$ works reasonably for the solubility of methane in methanol or MEG. ${ }^{107}$

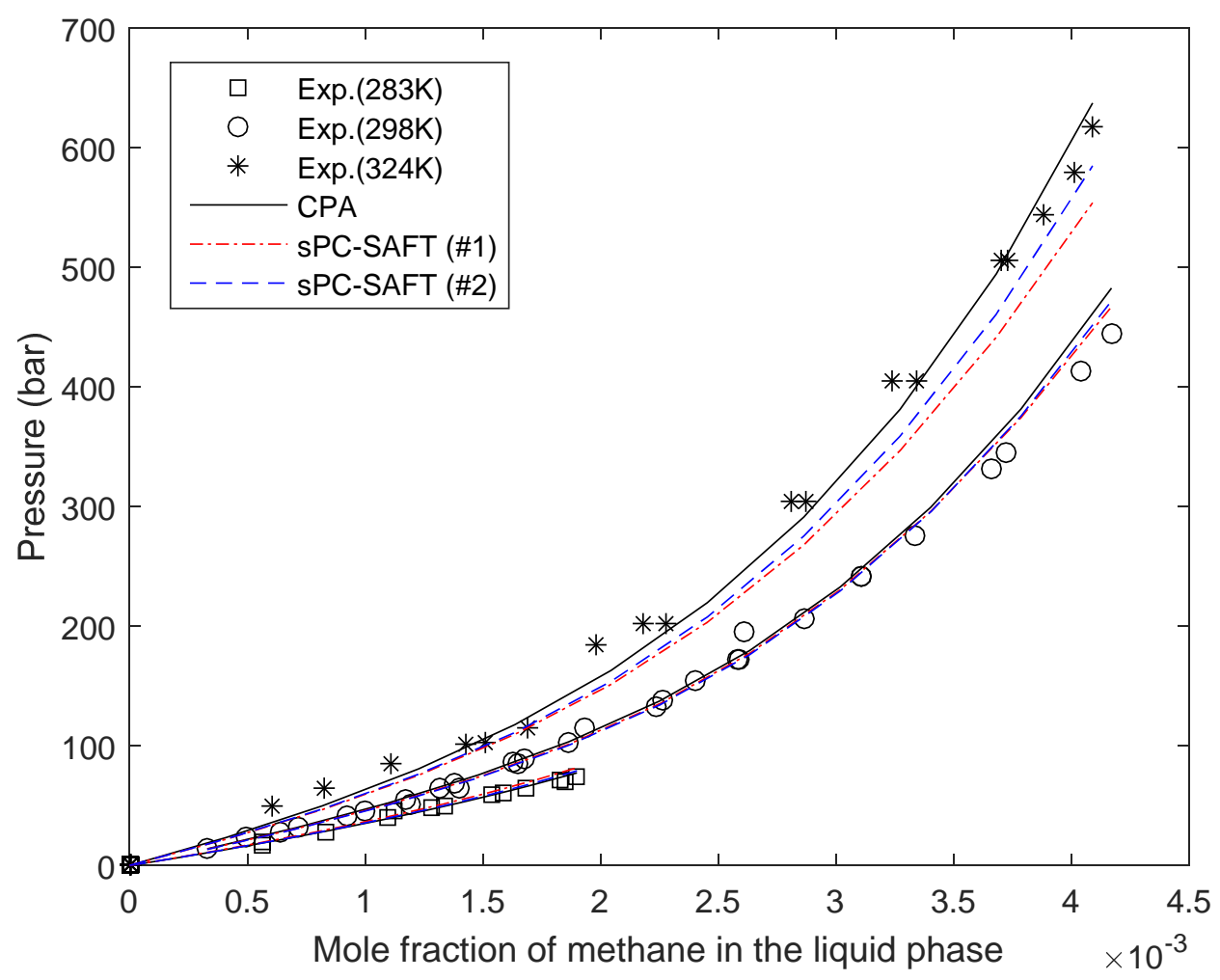

Figure 2. The correlated solubility of methane in water from the CPA and SPC-SAFT EOS. The binary interaction parameters are shown in Table 6. The experimental data are from Frost et al., ${ }^{25}$ Lekvam et al., ${ }^{27}$ Wang et al.,${ }^{28}$ Gao et al. ${ }^{29}$ and Culberson et al. ${ }^{30}$ 


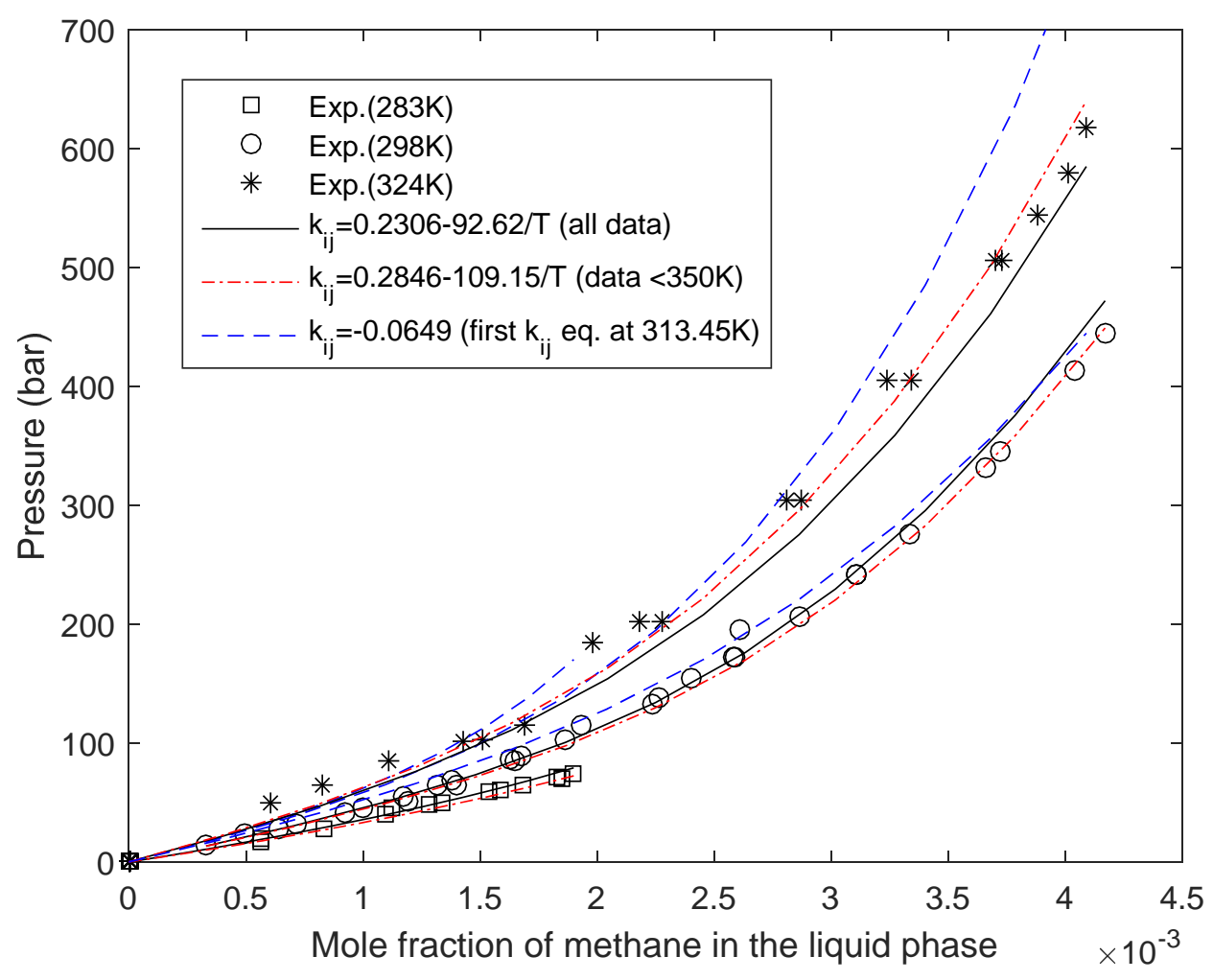

Figure 3. The solubility of methane in water from the sPC-SAFT EOS with three different $k_{i j}$ approaches. The experimental data are from Frost et al., ${ }^{25}$ Lekvam et al., ${ }^{27}$ Wang et al., ${ }^{28}$ Gao et al. ${ }^{29}$ and Culberson et al. ${ }^{30}$

The CPA and PC-SAFT EOS are not able to satisfactorily correlate the solubility of ethane in water, as seen in Table 6. A typical example is given in Figure 4 for three temperatures. The results at 293K are reasonable, while the results at $310 \mathrm{~K}$ and $344 \mathrm{~K}$ are not satisfactory, if compared with Figure 2, especially for the sPC-SAFT EOS. This may appear, at a first glance, rather surprising. It should be pointed out that the binary interaction parameter is tuned to the total pressure for all the data together, and it might be possible to correlate the data with more sophisticated temperature dependent binary interaction parameters, which might lead to worse predictive capabilities. The experimental solubilities of methane and ethane in water are compared in Figure 5. It can be seen that the pressure has little 
impact on the solubility of ethane in water above 50bar, while the solubility of methane increases gradually. There are not many data available for the solubility of ethane in water under high pressures. This suggests the need for more experimental measurements of this system under high pressures, which will help us understanding the different behaviors of methane and ethane in water.

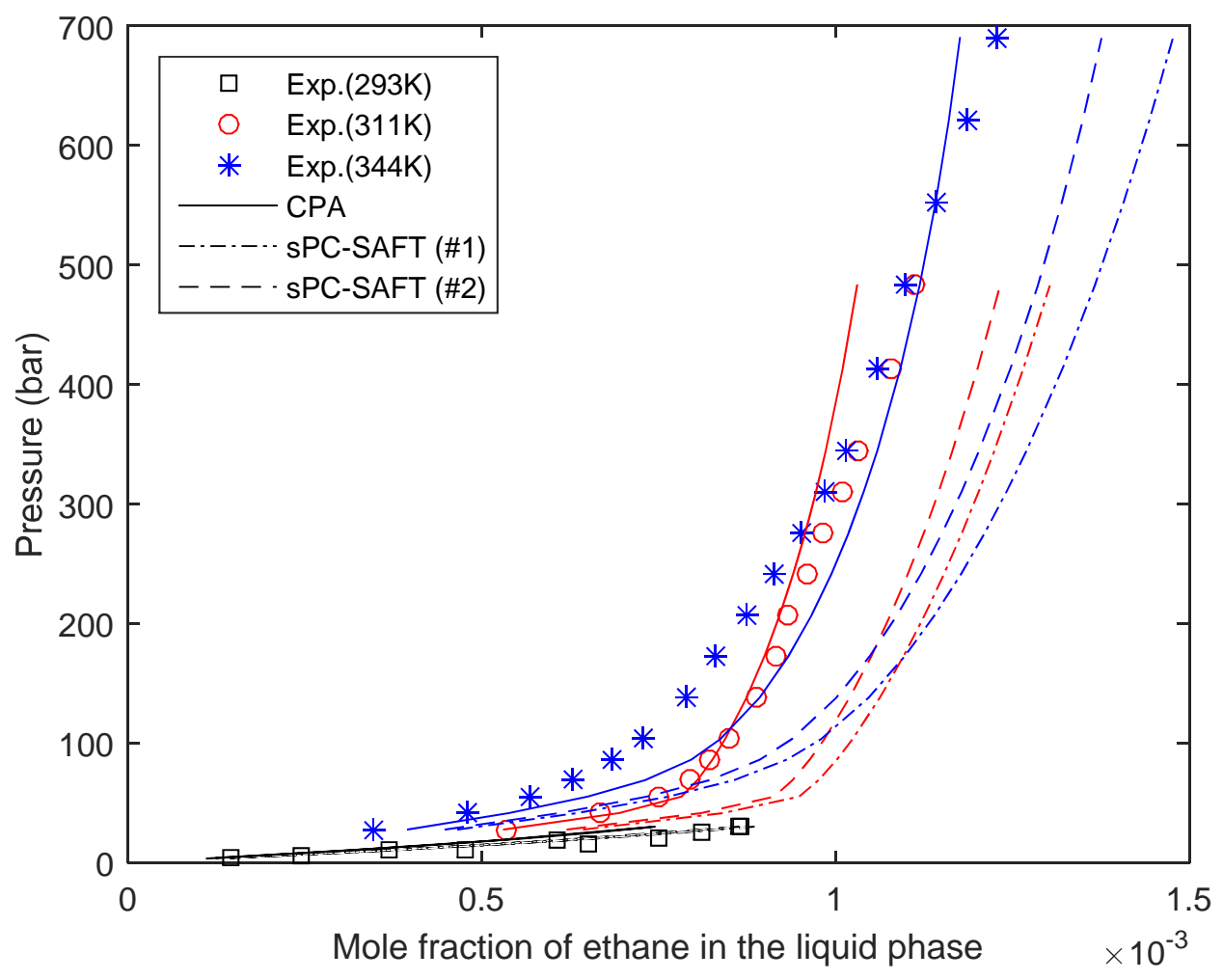

Figure 4. The solubility of ethane in water from the CPA and sPC-SAFT EOS. The binary interaction parameters are shown in Table 6. The experimental data are from Wang et al., ${ }^{28}$ Culberson et al. ${ }^{41}$ and Mohammadi et al. ${ }^{42}$ 


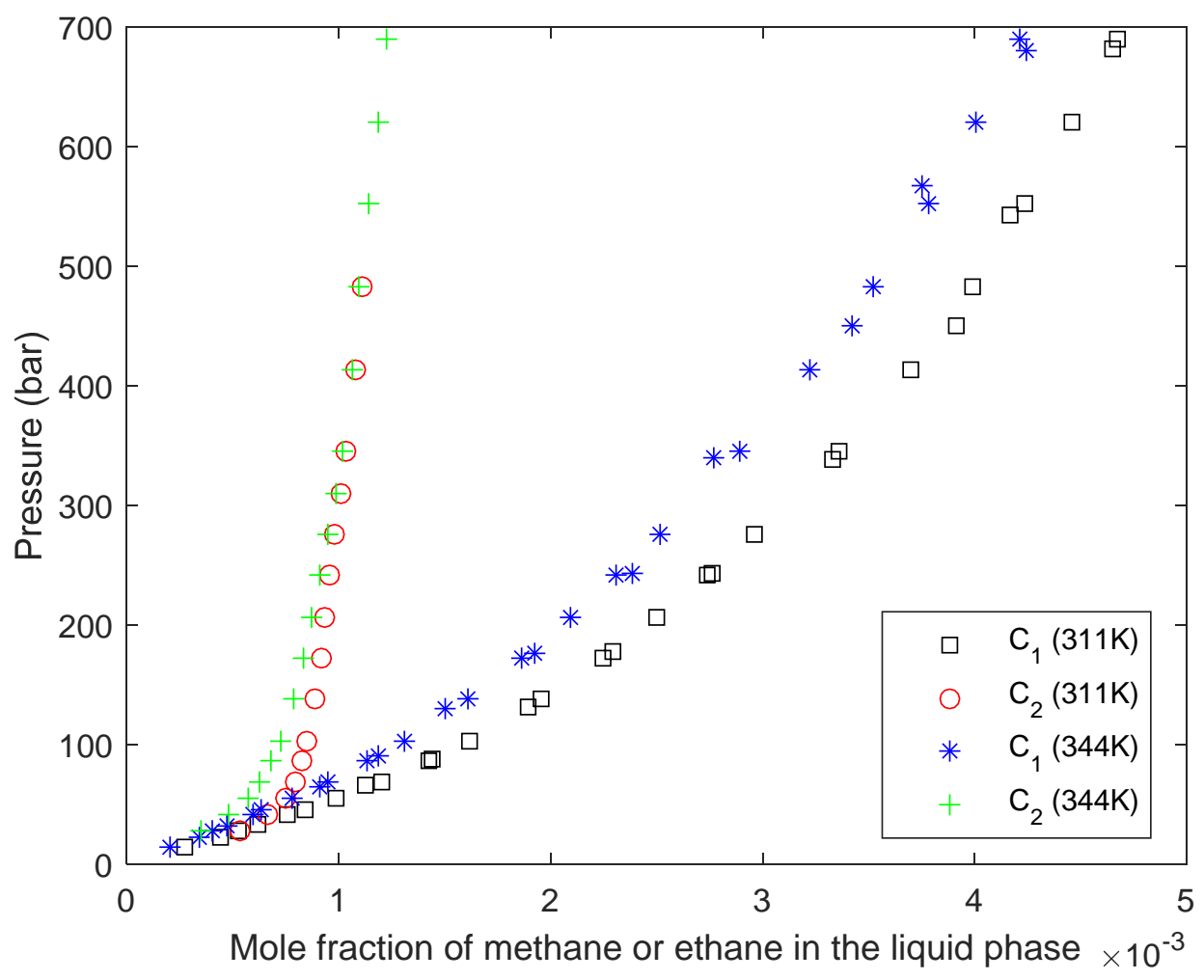

Figure 5. Comparison of experimental solubilities of methane and ethane in water at two temperatures. The experimental data are from Culberson et al. ${ }^{30,41}$ 
Physically the interaction between methanol and benzene is stronger than that of methanol and nhexane, because we do not see liquid-liquid phase split of methanol and benzene (as shown in Figure 6) while we have LLE of methanol and n-hexane under some circumstances (see below e.g. Figure 7). It can be seen from Table 6 that an extra adjustable parameter for the cross association volume can slightly reduce the \%AAD for the binary of methanol and benzene. With or without the cross association volume, however, it can be seen from Figure 6 that the modeling results are quite similar. In this sense, we may consider that solvation might not be necessary for modeling this binary.

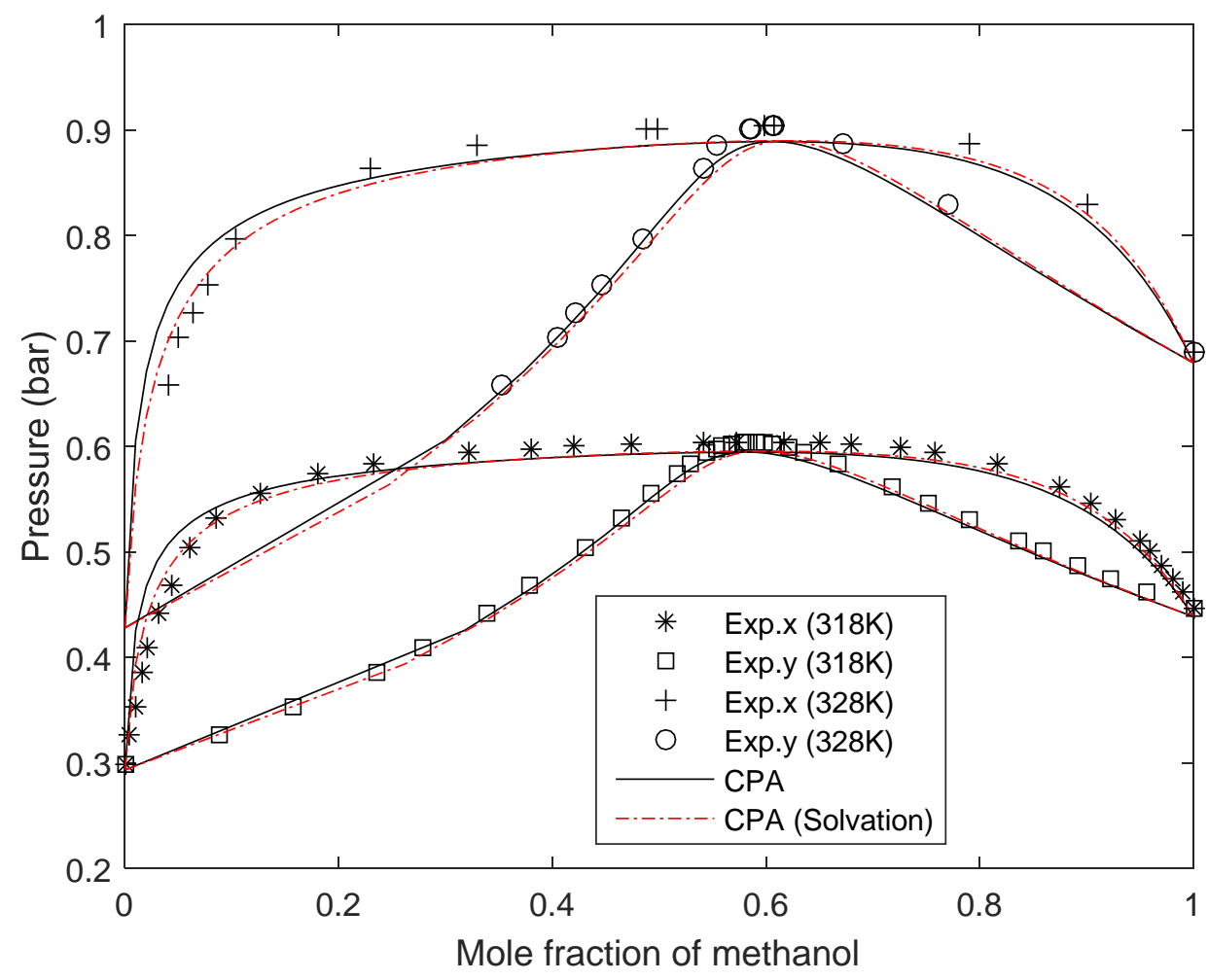

Figure 6. VLE of methanol-benzene from the CPA EOS with or without solvation. The binary interaction parameters are given in Table 6. The experimental data are from Toghiani et al. ${ }^{70}$ and Scatchard et al. ${ }^{71}$ 


\subsection{Binary Liquid-Liquid Equilibria (LLE)}

It is well-established that it is difficult to predict the LLE of binary polar + hydrocarbons systems. The results of some representative binary mixtures with correlated binary interaction parameters are presented in Table 7. Two adjustable binary interaction parameters are used when the hydrocarbon is aromatic. The \%AAD corresponds to compounds in the order listed in Table 7, i.e. the first row is for the deviation of the solubility of the hydrocarbon in the aqueous phase, and the second row is for the deviation of the solubility of the polar compound in the organic phase. The average \%AADs for each model and each phase are given in the last row of the table. Apparently the correlations of these binary mixtures are not as good as what have been seen in the VLE systems in Table 6. The results, however, can still be considered satisfactory. Again the CPA and sPC-SAFT EOS show quite similar performance in an overall point of view, while the first parameter set \#1 of the sPC-SAFT EOS gives a slightly larger overall deviation.

Table 7. LLE of polar-hydrocarbon systems with the CPA and sPC-SAFT models

\begin{tabular}{|c|c|c|c|c|c|c|c|c|}
\hline \multirow{2}{*}{$\mathrm{Np}$} & \multirow{2}{*}{ Temp. (K) } & \multirow{2}{*}{ System } & \multicolumn{3}{|c|}{$\frac{k_{i j}}{\kappa^{\text {cross }}}$} & \multicolumn{3}{|c|}{$\%$ AAD (mutual solubility) } \\
\hline & & & \multicolumn{2}{|c|}{ CPA } & \multicolumn{2}{|c|}{ sPC-SAFT (\#1) } & \multicolumn{2}{|c|}{ sPC-SAFT (\#2) } \\
\hline \multirow{2}{*}{23} & \multirow{2}{*}{$270.0-490.0$} & \multirow{2}{*}{$\begin{array}{c}\text { n-Hexane } \\
\text { Water }\end{array}$} & 0.0355 & 35 & 0.0488 & 49 & 0.0021 & 46 \\
\hline & & & & 9.9 & & 13 & & 6.1 \\
\hline \multirow{2}{*}{6} & \multirow{2}{*}{$278.15-303.15$} & n-Hexane & 0.01 & 47 & 0.0272 & 43 & 0.022 & 42 \\
\hline & & Methanol & & 12 & & 33 & & 12 \\
\hline \multirow{2}{*}{5} & \multirow{2}{*}{$307.95-330.35$} & n-Hexane & 0.059 & 5.9 & 0.043 & 9.7 & 0.040 & 3.7 \\
\hline & & MEG & & 11 & & 19 & & 4.2 \\
\hline \multirow{2}{*}{15} & \multirow{2}{*}{$279.15-453.15$} & Benzene & 0.0355 & 23 & 0.058 & 13 & 0.023 & 11 \\
\hline & & Water & 0.079 & 8.9 & 0.15 & 16 & 0.15 & 17 \\
\hline \multirow{2}{*}{6} & \multirow{2}{*}{$279.2-342.1$} & Benzene & 0.049 & 14 & 0.020 & 9.1 & 0.029 & 9.4 \\
\hline & & MEG & 0.0393 & 3.8 & 0.043 & 9.6 & 0.080 & 12 \\
\hline \multirow{2}{*}{16} & \multirow{2}{*}{$273.15-458.15$} & Toluene & 0.019 & 22 & 0.049 & 16 & 0.014 & 14 \\
\hline & & Water & 0.071 & 4.7 & 0.145 & 17 & 0.145 & 18 \\
\hline \multirow{3}{*}{10} & \multirow{2}{*}{$279.1-361.0$} & Toluene & 0.049 & 11 & 0.026 & 3.4 & 0.030 & 4.4 \\
\hline & & MEG & 0.039 & 4.3 & 0.051 & 6.1 & 0.083 & 8.6 \\
\hline & \multicolumn{2}{|c|}{ average $\% \mathrm{AAD}$} & & 15 & & 18 & & 15 \\
\hline
\end{tabular}


The LLE data of methanol-n-hexane have been reported by many groups. ${ }^{48-54}$ Figure 7 presents three data sets from different sources and the modeling results with the CPA and SPC-SAFT EOS. The data set 1 was measured under pressure $14 \mathrm{bar},{ }^{52}$ and the other two sets are at atmospheric pressure. ${ }^{51,53}$ It can be seen that the data are consistent with each other on the methanol rich polar phase, while there are significant differences on the n-hexane rich phase, especially when the methanol concentration is lower than 0.15 . This suggests a need for more systematic evaluation of the experimental data. It can also been seen that the CPA EOS presents larger deviations on the methanol rich side close to the cloud point, while the first parameter set \#1 of the sPC-SAFT EOS has difficulties in modeling the methanol lean branch.

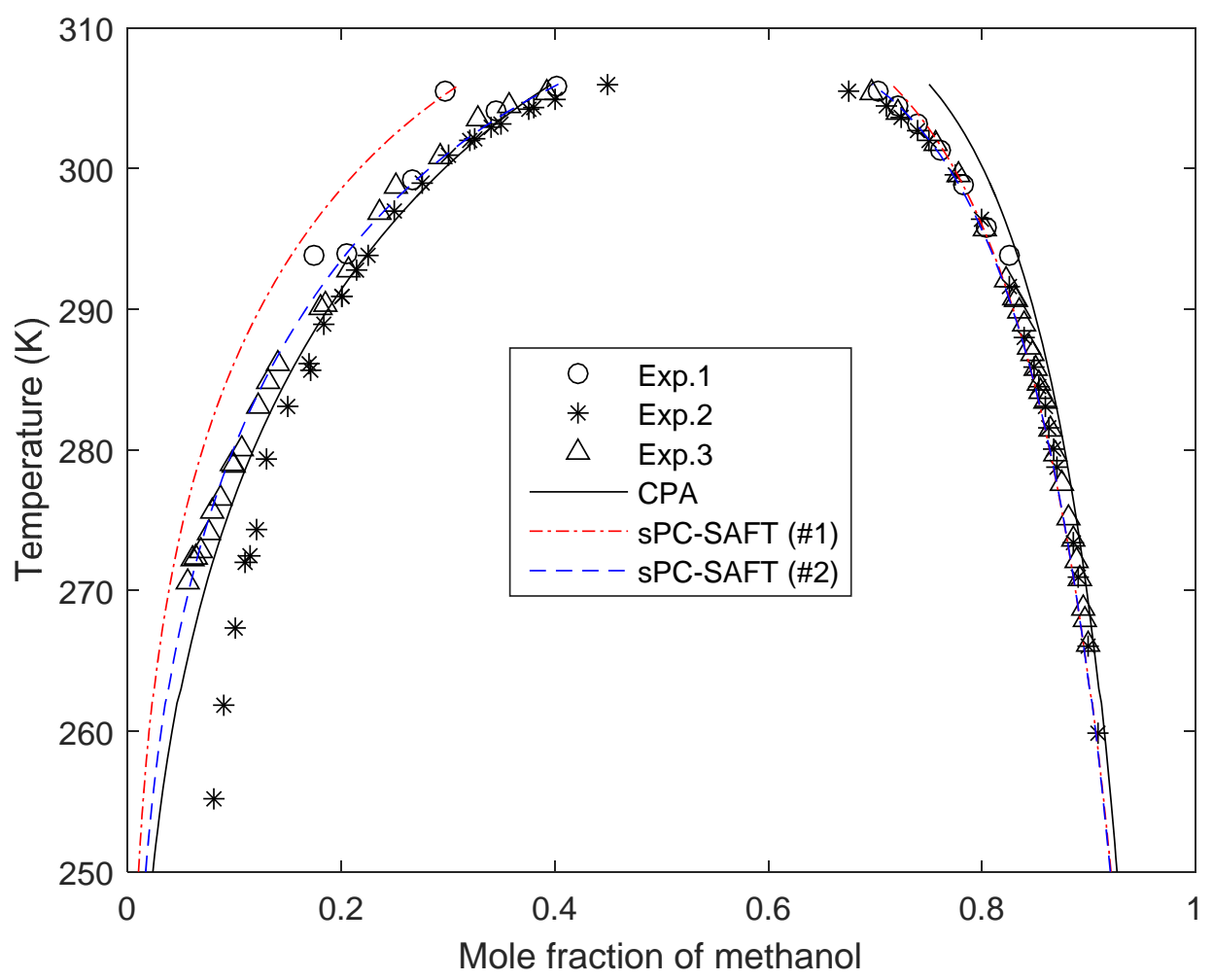

Figure 7. LLE of methanol-n-hexane from the CPA and sPC-SAFT EOS. The experimental data are from Blanco et al., ${ }^{52}$ Hradetzky et al. ${ }^{51}$ and Matsuda et al. ${ }^{53}$ The binary interaction parameters are shown in Table 7. 
Figure 8 presents the LLE of the binary mixture of water and benzene. The CPA EOS performs better in modeling the solubility of water in the organic phase, while PC-SAFT shows smaller deviations in modeling the solubility of benzene in the aqueous phase, especially at low to moderate temperatures with the currently investigated parameters. It should be pointed out that neither model can have correctly capture the minimum in the solubility of benzene, and the sPC-SAFT EOS shows larger deviations at higher temperatures.

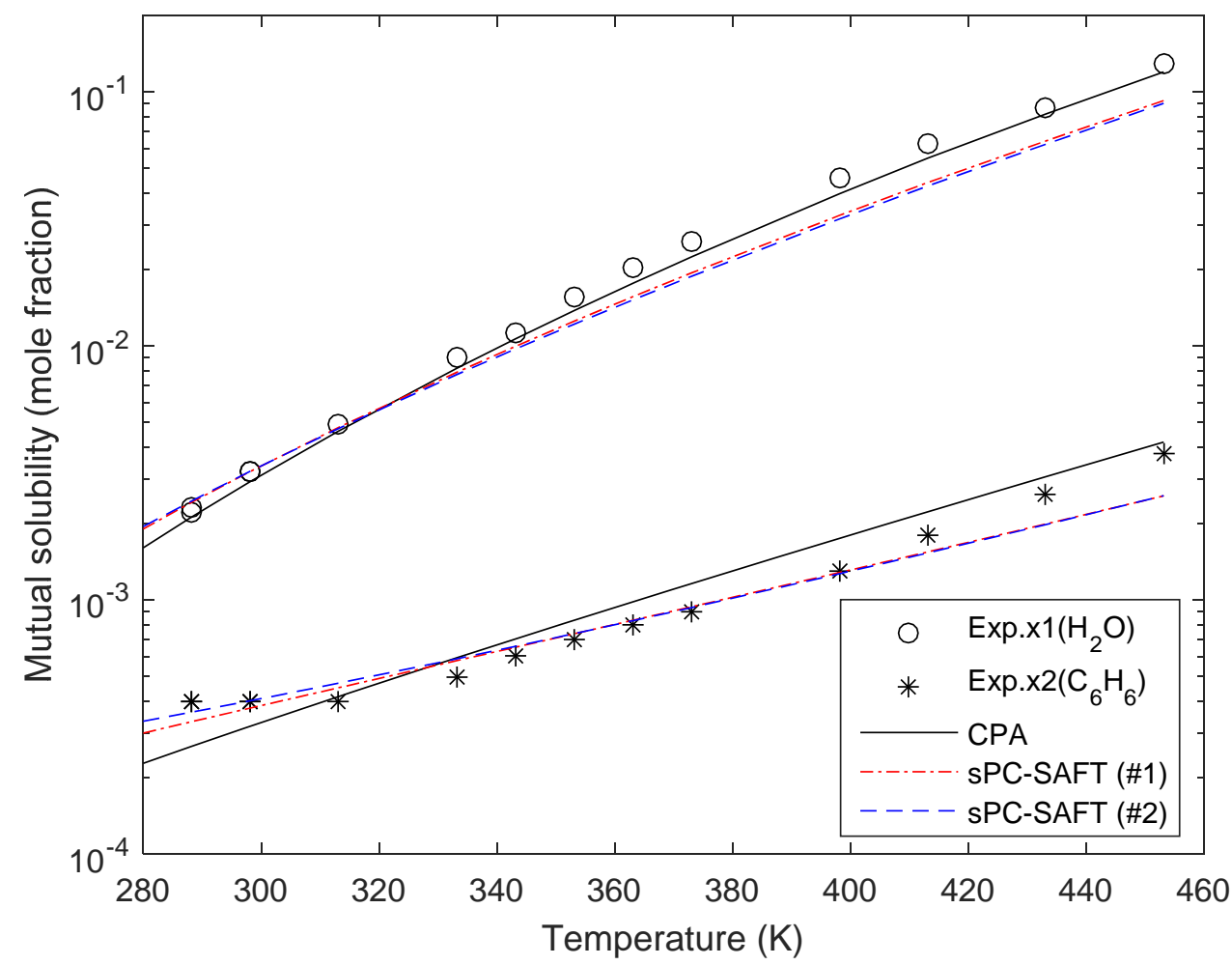

Figure 8. LLE of water-benzene from the CPA and SPC-SAFT EOS. The binary interaction parameters are shown in Table 7. The experimental data are from Jou et al. ${ }^{66}$ 
The models show similar behavior for the LLE of MEG-hydrocarbon, and one typical example for MEG-toluene is given in Figure 9. It shows that toluene is more soluble in MEG than MEG in toluene. With the given parameters, the CPA EOS performs better in modeling the solubility of MEG in toluene, while the sPC-SAFT EOS seems to be better for the other phase. The overall performance of the two models is again considered to be rather similar and quite satisfactory.

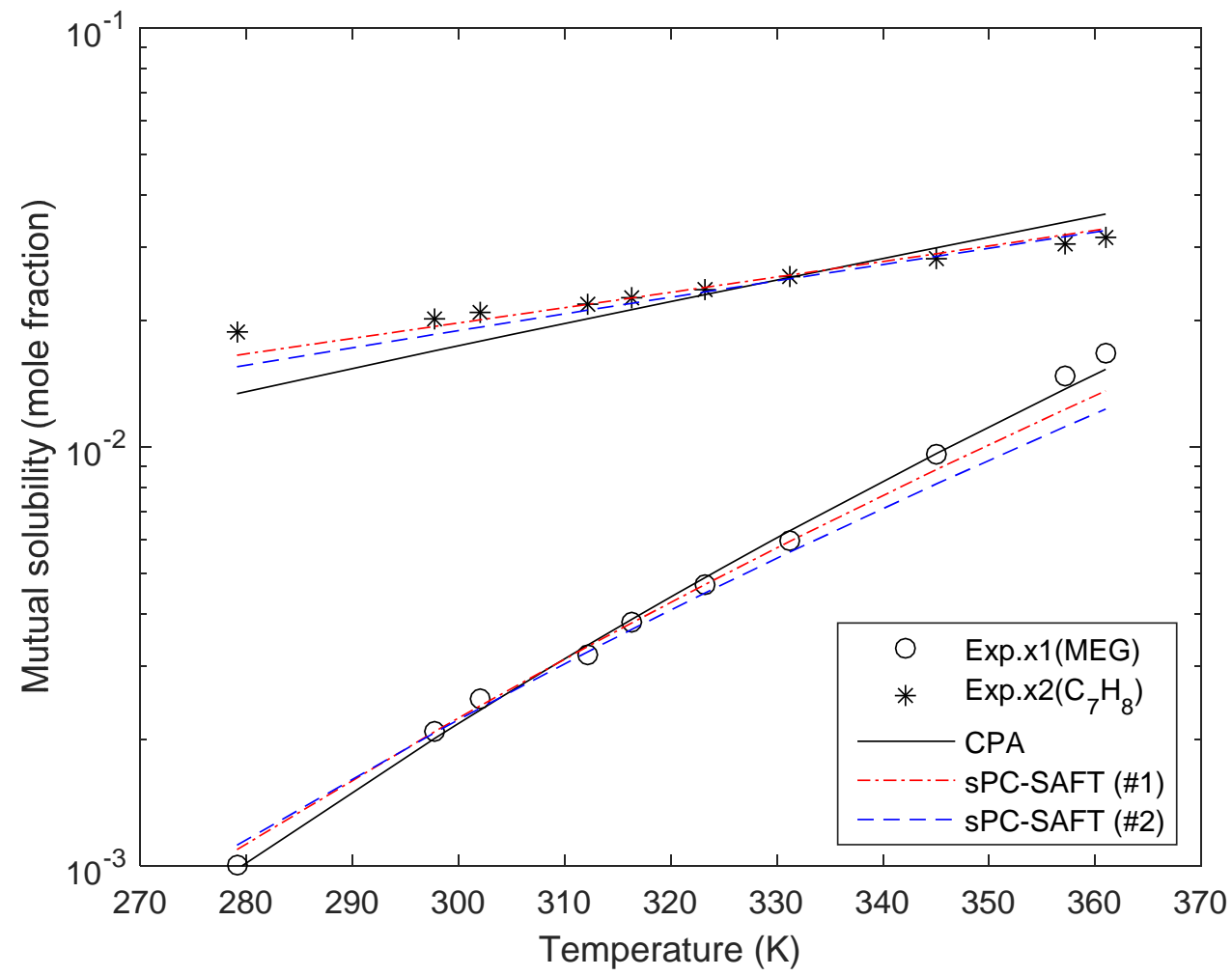

Figure 9. LLE of MEG-toluene from the CPA and sPC-SAFT EOS. The binary interaction parameters are shown in Table 7. The experimental data are from Folas et al. ${ }^{77}$ 


\subsection{Multicomponent fluid phase equilibria}

When the pure component parameters and binary interaction parameters are available, we can investigate the predictive capabilities of the models, i.e. the predictions of multicomponent multiphase equilibria using solely binary parameters estimated from binary data. The predicted results of the VLE of water-methanol/MEG-methane are given in Table 8. Apparently the two models show quite similar performance with all parameter sets.

Table 8. \%AAD of composition in the VLE of ternary mixtures

\begin{tabular}{|c|c|c|c|c|c|c|c|}
\hline \multirow[b]{2}{*}{$\begin{array}{l}\mathrm{T}(\mathrm{K}) \\
(\mathrm{Np})\end{array}$} & \multirow[b]{2}{*}{ Systems } & \multicolumn{3}{|c|}{ Aqueous phase } & \multicolumn{3}{|c|}{ Vapor phase } \\
\hline & & CPA & $\begin{array}{l}\text { sPC-SAFT } \\
(\# 1)\end{array}$ & $\begin{array}{c}\text { sPC-SAFT } \\
(\# 2)\end{array}$ & CPA & $\begin{array}{l}\text { sPC-SAFT } \\
(\# 1)\end{array}$ & $\begin{array}{c}\text { sPC-SAFT } \\
(\# 2)\end{array}$ \\
\hline \multirow{12}{*}{$\begin{array}{c}280.25- \\
313.45 \\
(\mathrm{~Np}=105)\end{array}$} & Methane & 35 & 26 & 32 & 0.009 & 0.011 & 0.007 \\
\hline & Water & 0.4 & 0.3 & 0.3 & 22 & 19 & 15 \\
\hline & Methanol & 0.7 & 0.5 & 0.7 & 2.8 & 6.6 & 1.2 \\
\hline & $k_{12}$ & \multicolumn{6}{|c|}{ the first case in Table 6} \\
\hline & Methane & 35 & 30 & 35 & 0.009 & 0.011 & 0.007 \\
\hline & Water & 0.4 & 0.3 & 0.4 & 22 & 18 & 14 \\
\hline & Methanol & 0.7 & 0.6 & 0.7 & 2.8 & 6.7 & 1.2 \\
\hline & $k_{12}$ & \multicolumn{6}{|c|}{ the second case in Table 6} \\
\hline & Methane & 18 & 14 & 18 & 0.009 & 0.0112 & 0.007 \\
\hline & Water & 0.2 & 0.2 & 0.2 & 25 & 20 & 17 \\
\hline & Methanol & 0.5 & 0.4 & 0.5 & 3.1 & 6.5 & 1.2 \\
\hline & $k_{12}$ & 0.0443 & 0.0108 & -0.0649 & & & \\
\hline \multirow{12}{*}{$\begin{array}{c}283.2- \\
303.2 \\
(\mathrm{~Np}=92)\end{array}$} & Methane & 24 & 30 & 29 & - & - & - \\
\hline & Water & 0.1 & 0.1 & 0.1 & - & - & - \\
\hline & MEG & 0.1 & 0.1 & 0.1 & - & - & - \\
\hline & $k_{12}$ & \multicolumn{6}{|c|}{ the first case in Table 6} \\
\hline & Methane & 24 & 33 & 31 & - & - & - \\
\hline & Water & 0.1 & 0.2 & 0.1 & - & - & - \\
\hline & MEG & 0.1 & 0.1 & 0.1 & - & - & - \\
\hline & $k_{12}$ & \multicolumn{6}{|c|}{ second case in Table 6} \\
\hline & Methane & 15 & 20 & 18 & - & - & - \\
\hline & Water & 0.1 & 0.1 & 0.1 & - & - & - \\
\hline & MEG & 0.1 & 0.1 & 0.1 & - & - & - \\
\hline & $k_{12}$ & 0.0443 & 0.0108 & -0.0649 & - & - & - \\
\hline $\begin{array}{l}\text { average } \\
\% \text { AAD }\end{array}$ & & 8.6 & 8.7 & 9.2 & 8.6 & 8.5 & 5.5 \\
\hline
\end{tabular}


Three options of the binary interaction parameter between water and methane, i.e. a temperature dependent $k_{i j}$ covering data up to $450 \mathrm{~K}$, a temperature dependent $k_{i j}$ covering data only up to $350 \mathrm{~K}$ and a constant $k_{i j}$, have been investigated. The two temperature dependent $k_{i j}$ sets show similar performance as seen for this binary mixture. However, we have surprisingly found that a constant $k_{i j}$ significantly improves the predictions of the solubility of methane in the aqueous phase without deteriorating the other phase. It is important to recall that a constant $k_{i j}$ does not describe the binary mixture of water and methane well, as discussed in Figure 3 above. This might be a coincidence, as we see from Figure 10 that the constant $k_{i j}$ underpredicts and overpredicts the solubility of methane in the liquid phase at $283.2 \mathrm{~K}$ and $303.2 \mathrm{~K}$, respectively. Therefore, a temperature dependent $k_{i j}$ is still recommended if wide temperature applications are concerned.

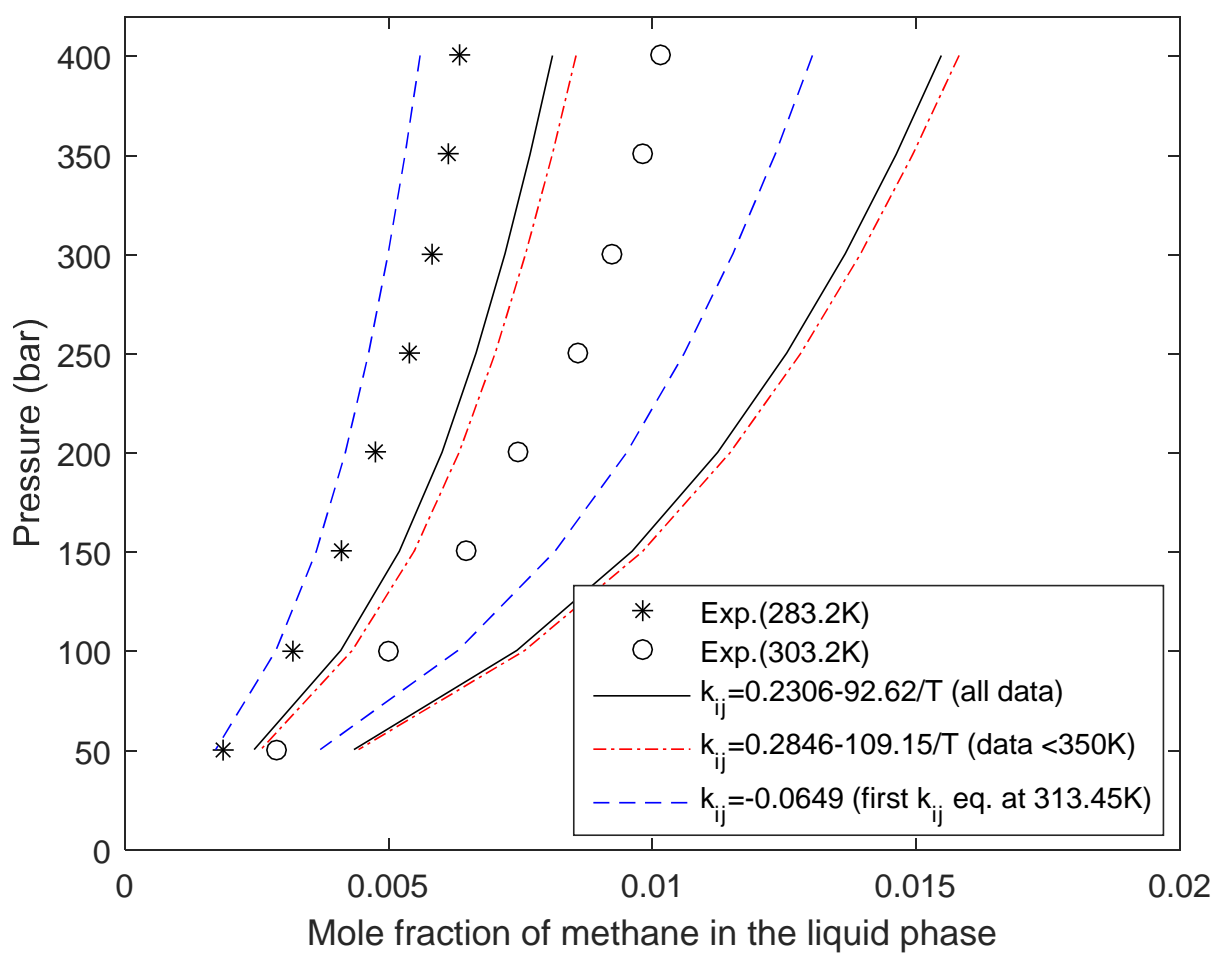

Figure 10. The solubility of methane in the solution of methanol and water from the sPC-SAFT EOS (set \#2) with different $k_{i j}$ approaches. The experimental data are from Wang et al. ${ }^{28}$ 
The deviations of the predicted LLE results of water-methanol/MEG-n-hexane/benzene/toluene are presented in Table 9. The deviations are given corresponding to the component list as in Table 8 . The average \%AADs for each model and each phase are added in the last row of the table as well. The models again show comparable performances, even though a slightly larger deviation is seen for the first parameter set \#1 of the sPC-SAFT EOS.

Table 9. \%AAD of composition in the LLE of ternary mixtures

\begin{tabular}{|c|c|c|c|c|c|c|c|}
\hline \multirow[b]{2}{*}{$\mathrm{T}(\mathrm{K})$} & \multirow[b]{2}{*}{ Systems } & \multicolumn{3}{|c|}{ Aqueous phase } & \multicolumn{3}{|c|}{ Organic phase } \\
\hline & & CPA & $\begin{array}{c}\text { sPC-SAFT } \\
(\# 1)\end{array}$ & $\begin{array}{c}\text { sPC-SAFT } \\
(\# 2)\end{array}$ & CPA & $\begin{array}{c}\text { sPC-SAFT } \\
(\# 1)\end{array}$ & $\begin{array}{c}\text { sPC-SAFT } \\
(\# 2)\end{array}$ \\
\hline 293.15- & n-Hexane & 29 & 22 & 22 & 2.0 & 2.1 & 1.6 \\
\hline 318.15 & Water & 8.0 & 4.5 & 5.8 & 69 & 75 & 68 \\
\hline $\mathrm{Np}=81$ & Methanol & 1.9 & 1.2 & 1.4 & 56 & 30 & 35 \\
\hline $283.15-$ & n-Hexane & 37 & 23 & 20 & 0.017 & 0.019 & 0.010 \\
\hline 323.15 & Water & 0.012 & 0.009 & 0.015 & 43 & 50 & 31 \\
\hline $\mathrm{Np}=24$ & MEG & 0.029 & 0.021 & 0.031 & 17 & 42 & 23 \\
\hline \multirow{8}{*}{$\begin{array}{l}293.15- \\
333.15 \\
\mathrm{~Np}=62\end{array}$} & Benzene & 31 & 40 & 39 & 6.5 & 6.3 & 5.7 \\
\hline & Water & 7.9 & 9.2 & 9.8 & 33 & 35 & 34 \\
\hline & Methanol & 4.8 & 6.3 & 6.4 & 42 & 44 & 44 \\
\hline & \multicolumn{7}{|c|}{ Solvation is used for methanol and benzene } \\
\hline & Benzene & 28 & 28 & 30 & 6.9 & 9.1 & 7.6 \\
\hline & Water & 6.2 & 4.2 & 5.2 & 32 & 37 & 33 \\
\hline & Methanol & 3.6 & 2.3 & 2.7 & 44 & 54 & 48 \\
\hline & \multicolumn{7}{|c|}{ No solvation is used for methanol and benzene } \\
\hline $298.2-$ & Benzene & 19 & 27 & 21 & 0.012 & 0.013 & 0.016 \\
\hline 323.2 & Water & 0.2 & 0.3 & 0.2 & 8.0 & 6.3 & 5.2 \\
\hline $\mathrm{Np}=10$ & MEG & 0.2 & 0.2 & 0.2 & 14 & 7.9 & 19 \\
\hline $298.2-$ & Toluene & 18 & 15 & 15 & 0.006 & 0.016 & 0.014 \\
\hline 323.2 & Water & 0.044 & 0.026 & 0.025 & 3.9 & 4.6 & 2.6 \\
\hline $\mathrm{Np}=8$ & MEG & 0.11 & 0.07 & 0.066 & 7.6 & 9.1 & 12 \\
\hline averag & $\% A A D$ & 11 & 10 & 10 & 21 & 23 & 21 \\
\hline
\end{tabular}


The performances of the models are generally considered to be satisfactory, but it can be seen that deviations of the solubilities of water and methanol in the n-hexane rich organic phase are relatively large. The modeling results of this system at two conditions are presented in Figures 11 and 12, for which the data are from different sources. The models give very satisfactory predictions for all the components in Figure 11, while they poorly predict the solubilities of water and methanol in the organic phase in Figure 12. It can be recognized that the solubility of water shown in Figure 12 is almost one order magnitude higher than those shown in Figure 11, and it is closer to the solubility of water in benzene, as given in Figure 13. This suggests once again the need for further data validation, e.g. for making new and systematic measurements for this system under these conditions.

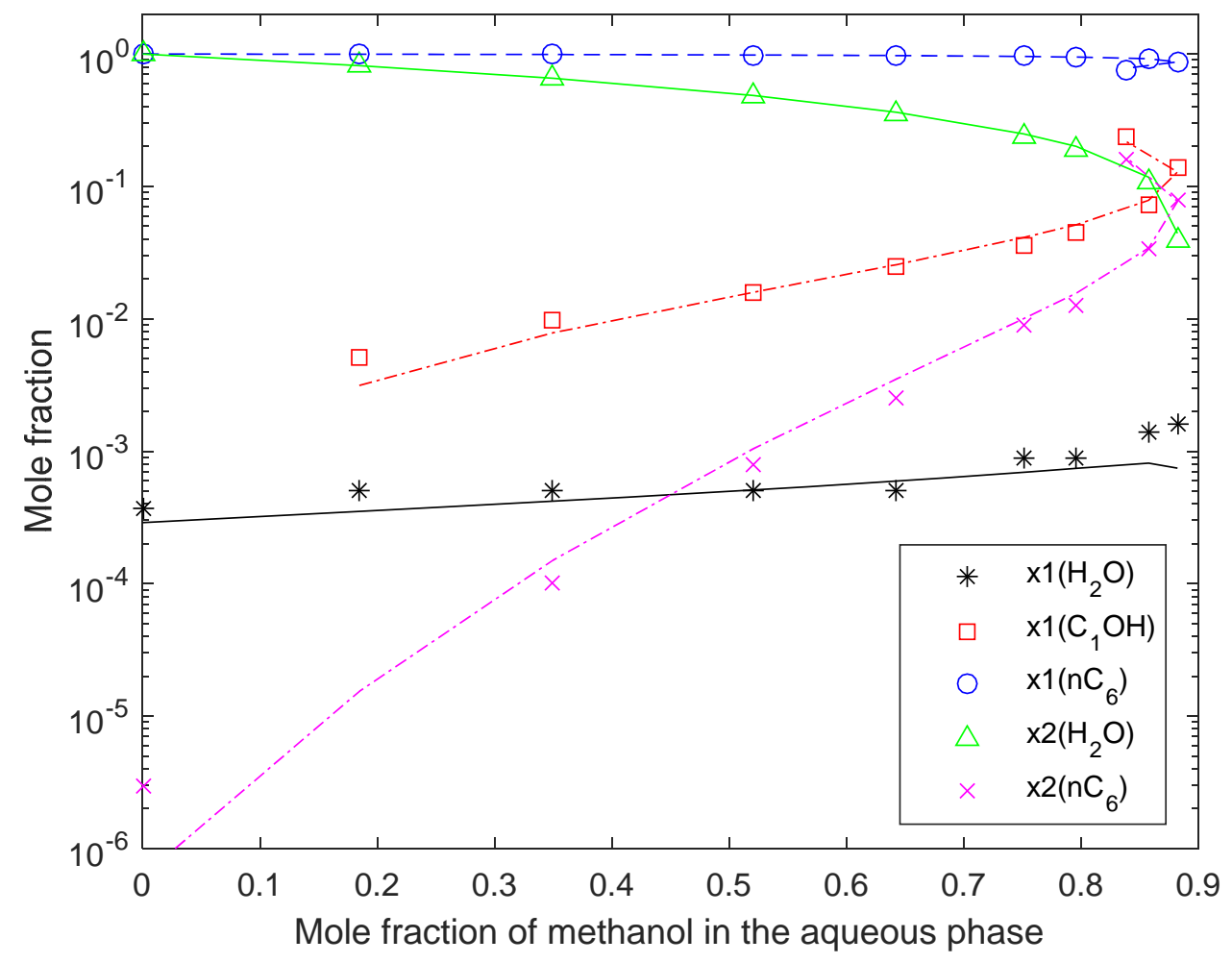

Figure 11. LLE of water-methanol-n-hexane at 293.2K from the CPA EOS. The experimental data are from Skrzecz et al. ${ }^{87}$ The binary interaction parameters are shown in Tables 6 and 7 . 


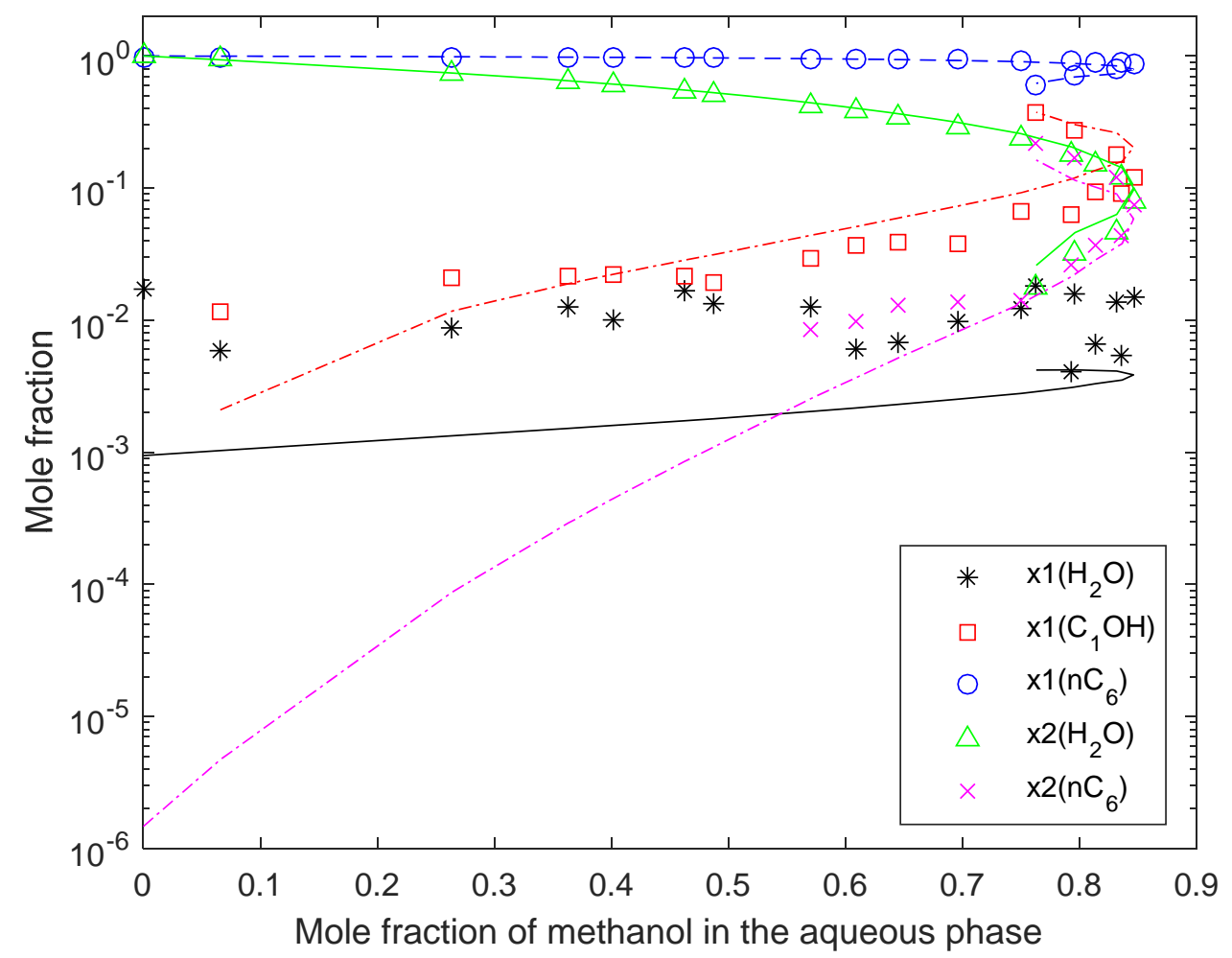

Figure 12. LLE of water-methanol-n-hexane at 318.15K from the CPA EOS. The experimental data are from Liu et al. ${ }^{88}$ The interaction parameters are shown in Tables 6 and 7. 
As discussed above (e.g. in Figure 6), solvation between methanol and benzene has insignificant effects on the VLE of the binary mixture. It is shown in Figure 13 that the solvation can slightly move the solubility lines, i.e. bringing more methanol into the organic phase and less benzene into the aqueous phase. As indicated by the \%AAD given in Table 9 solvation between methanol and benzene has a small impact on modeling the system of water-methanol-benzene as well from an overall point of view. Therefore, as an alternative, solvation could be used for water and benzene only. As shown in Figure 6, more measurements for the binary methanol and benzene at low concentration range of methanol may be useful and may actually lead to somewhat different conclusions.

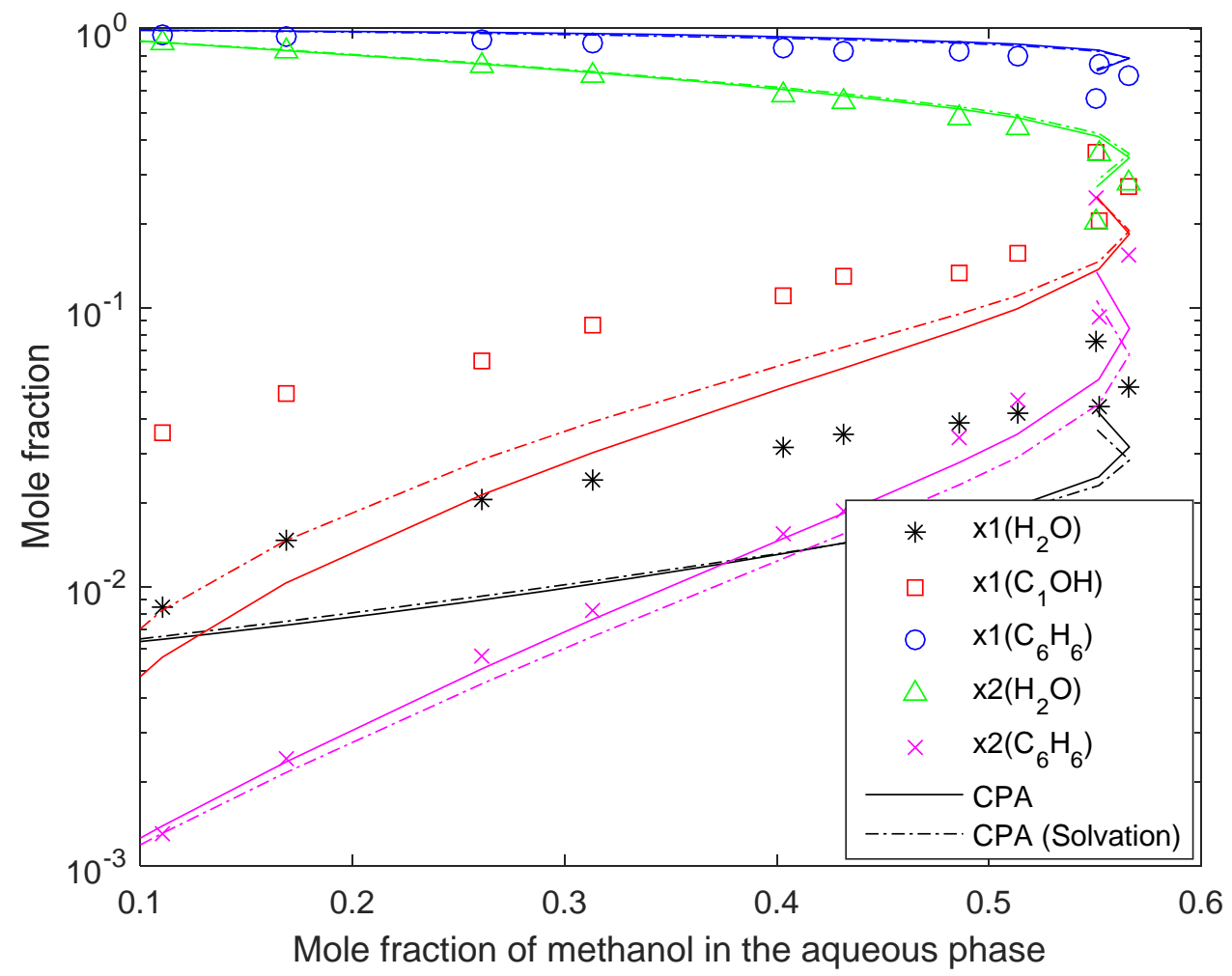

Figure 13. LLE of water-methanol-benzene from the CPA EOS with or without solvation between benzene and methanol at 318.15K. The interaction parameters are shown in Tables 6 and 7. 
The performance of these models and parameters are further tested in predicting the fluid phase equilibria of quaternary mixtures. The results for two mixtures are presented in Figures 14 and 15 and the deviations are listed in Table 10. Both systems contain water, MEG and methane. The last component is n-hexane in the first mixture and toluene in the second one. Solvation is used for both MEG-toluene and water-toluene. The two models show similar performance for these systems, especially for the vapor phase and the aqueous phase, and the only exception might be an underprediction of the solubility of MEG in the organic phase of the second quaternary mixture from the CPA EOS. The modeling results, in general terms, are satisfactory, except both models underpredict the solubility of n-hexane in the aqueous phase, as shown in Figure 14. Both models overpredict the solubility of toluene in the aqueous phase at $263.15 \mathrm{~K}$ in Figure 15 , in which case the qualitative behavior is opposite against the data. This suggests that more measurements are needed to further verify the data and validate the model.

Table 10. Vapor-liquid-liquid equilibria of two quaternary mixtures

\begin{tabular}{|c|c|c|c|c|c|c|c|}
\hline \multirow{3}{*}{$\begin{array}{c}\text { Temperature } \\
(\mathrm{K})\end{array}$} & \multirow{3}{*}{ Comp. } & \multicolumn{6}{|c|}{$\% \mathrm{AAD}$ of mole fraction } \\
\hline & & \multicolumn{2}{|r|}{ Vapor } & \multicolumn{2}{|c|}{ Organic } & \multicolumn{2}{|c|}{ Aqueous } \\
\hline & & CPA & $\begin{array}{c}\text { sPC-SAFT } \\
(\# 2)\end{array}$ & CPA & $\begin{array}{c}\text { sPC-SAFT } \\
(\# 2)\end{array}$ & CPA & $\begin{array}{c}\text { sPC-SAFT } \\
(\# 2)\end{array}$ \\
\hline & $\mathrm{H} 2 \mathrm{O}$ & - & - & 38 & 14 & 0.06 & 0.05 \\
\hline $263.15-$ & MEG & - & - & 52 & 34 & 0.49 & 0.49 \\
\hline \multirow{2}{*}{283.15} & $\mathrm{C} 1$ & 0.04 & 0.03 & 1.4 & 5.3 & 33 & 35 \\
\hline & nC6 & 9.8 & 4.2 & 2.4 & 4.5 & 94 & 88 \\
\hline & $\mathrm{H} 2 \mathrm{O}$ & 44 & 38 & 18 & 13 & 0.06 & 0.06 \\
\hline $263.15-$ & MEG & - & - & 90 & 23 & 0.12 & 0.02 \\
\hline \multirow[t]{2}{*}{323.15} & $\mathrm{C} 1$ & 0.02 & 0.03 & 13 & 17 & 11 & 14 \\
\hline & Toluene & 3.0 & 10 & 2.9 & 3.6 & 1121 & 2152 \\
\hline average \%AAD ${ }^{*}$ & & 11 & 10 & 27 & 14 & 20 & 20 \\
\hline
\end{tabular}

* The average \%AADs of the aqueous phase do not count the solubility of toluene, since one point largely overpredicted. 

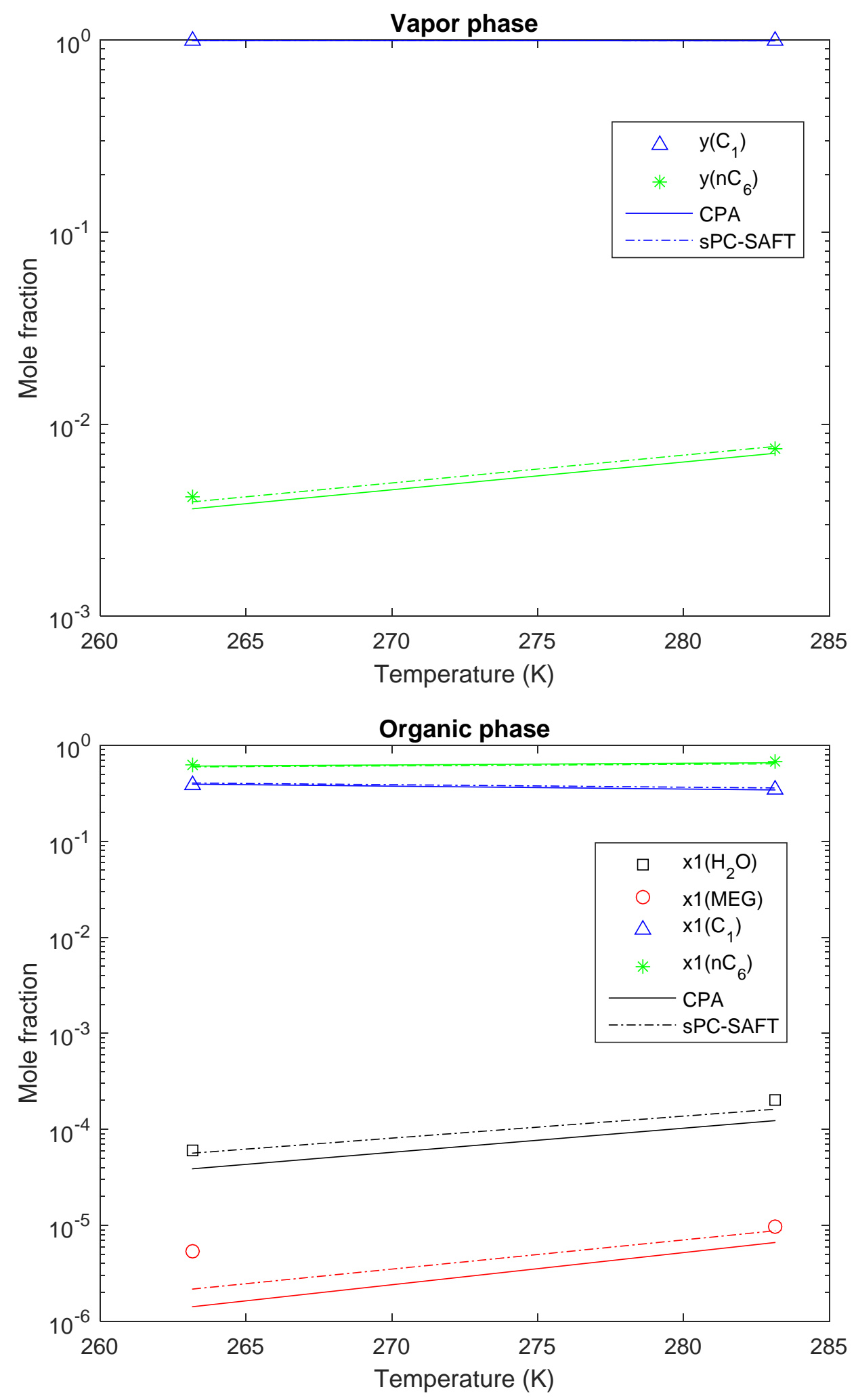


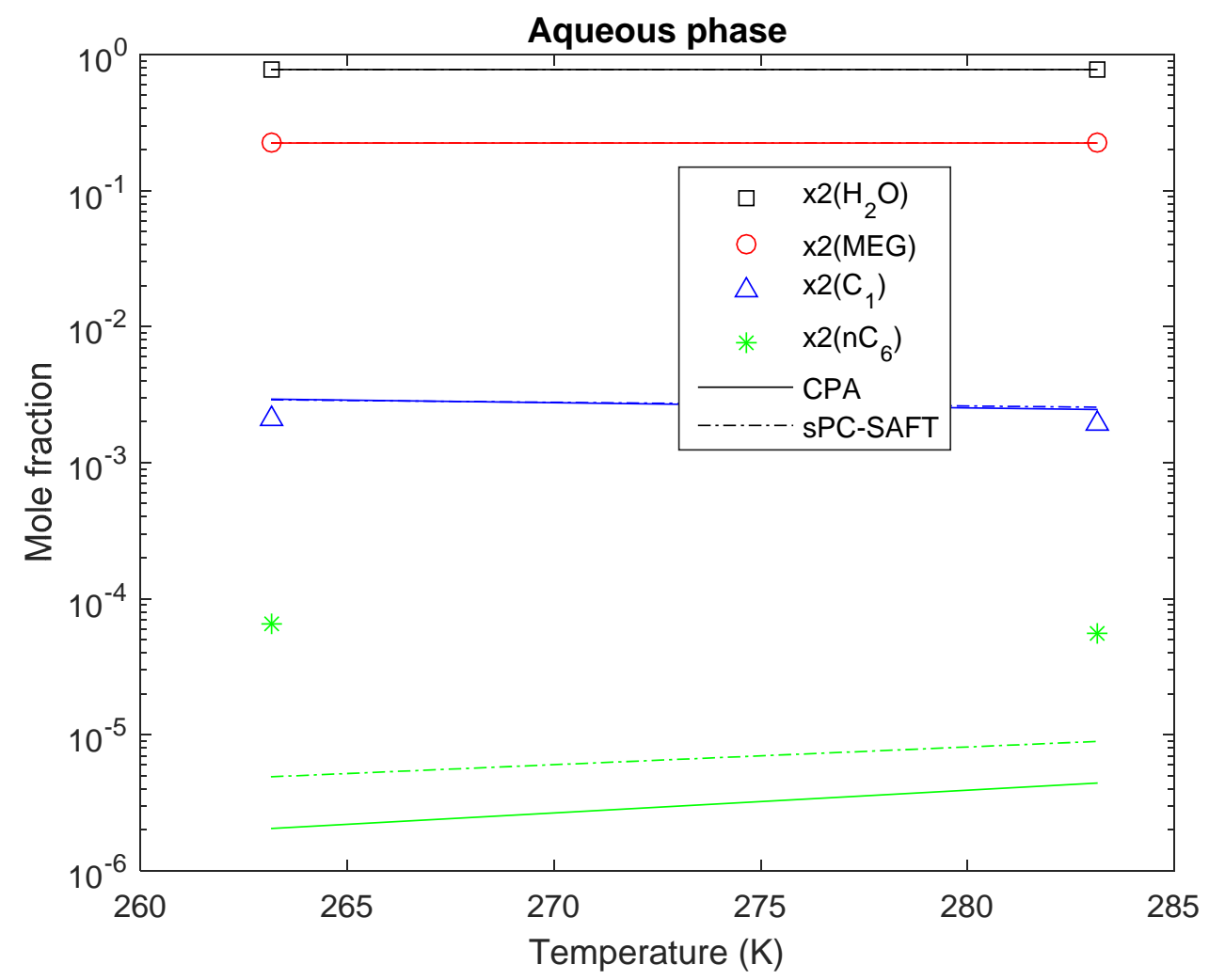

Figure 14. VLLE of water-MEG-methane-n-hexane at $263.15 \mathrm{~K}$ and $283.15 \mathrm{~K}$. Solid and dash-dot lines are modeling results from the CPA and SPC-SAFT EOS, respectively. The parameter set \#2 is used for the SPC-SAFT EOS. 

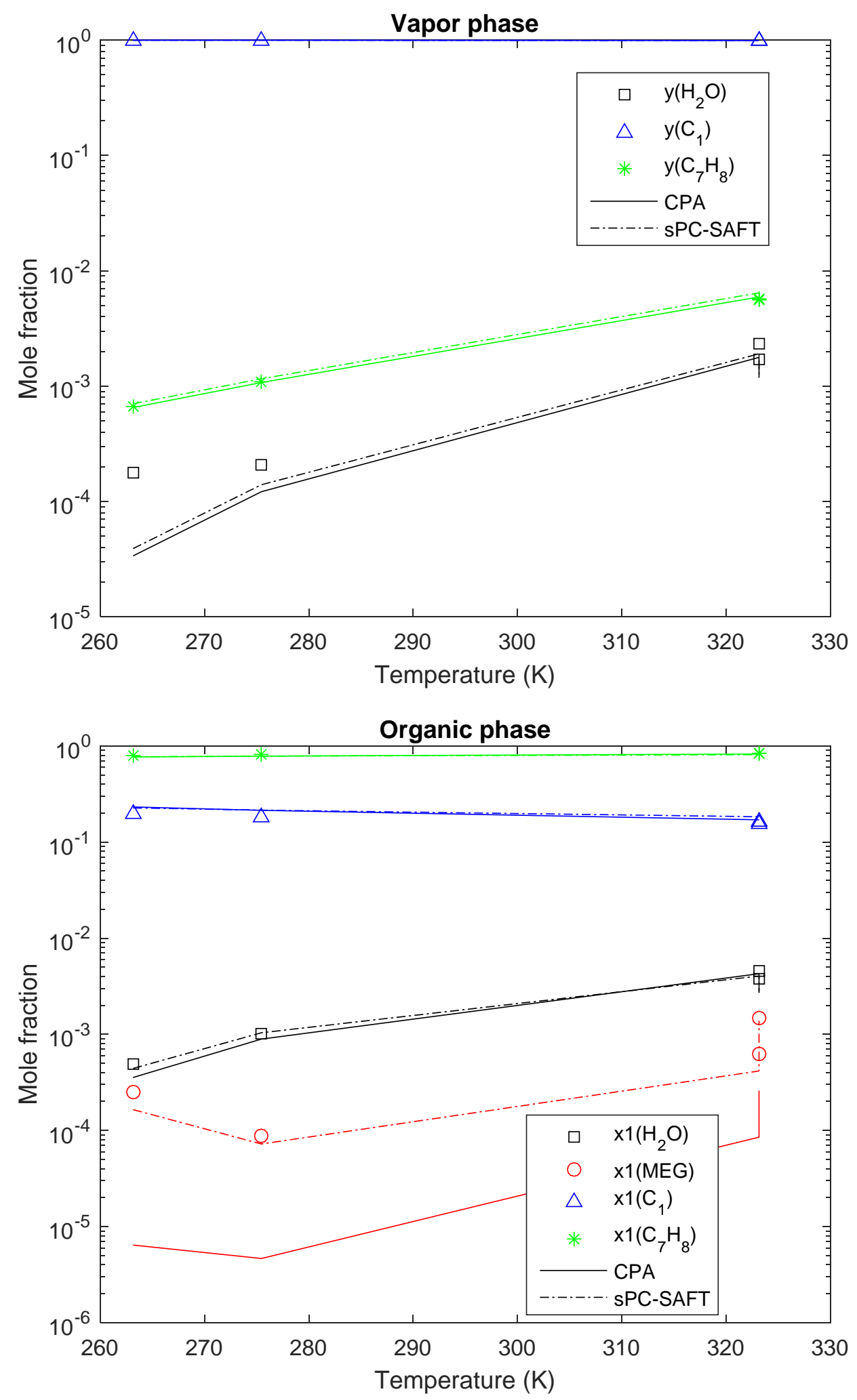


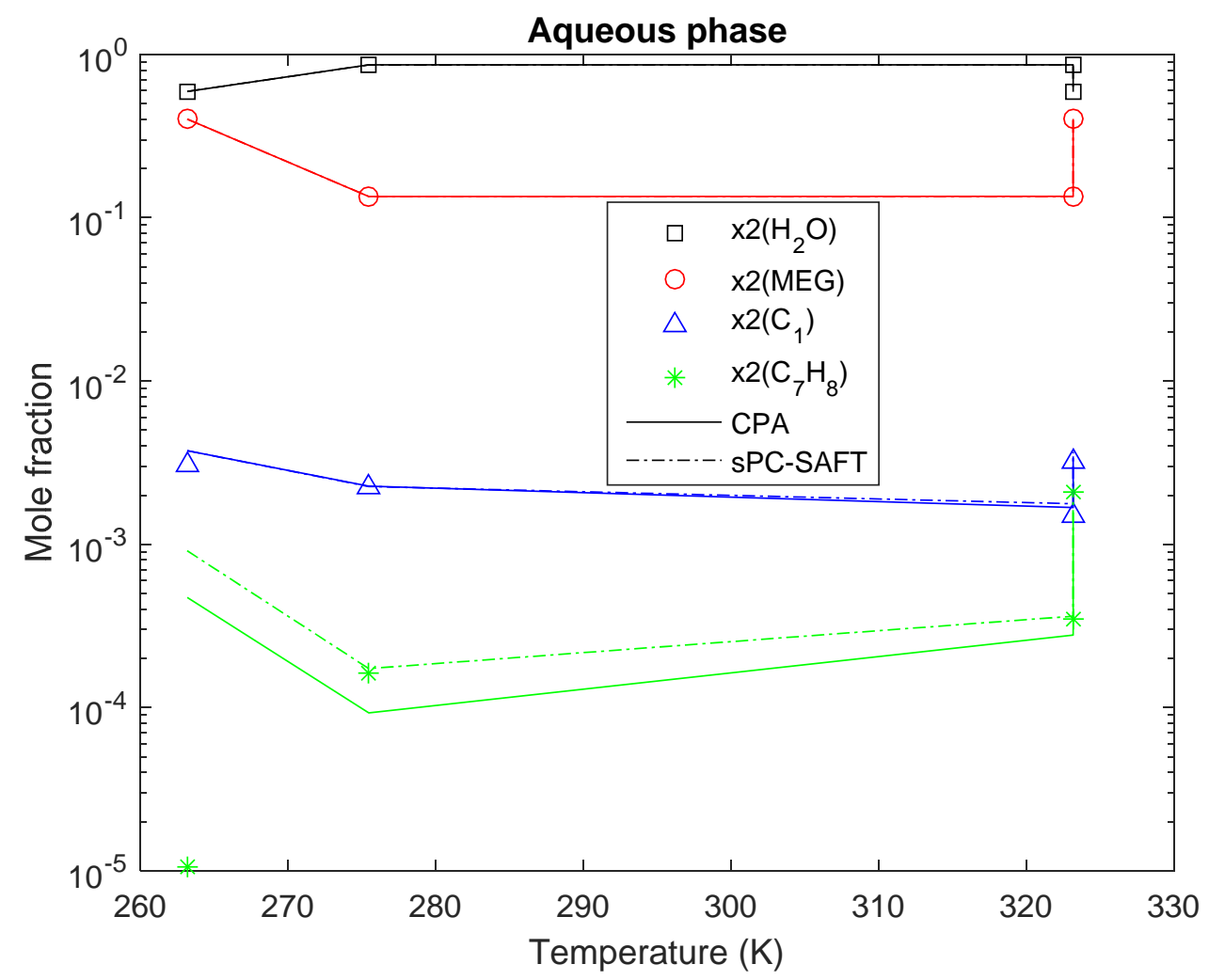

Figure 15. VLLE of water-MEG-methane-toluene from $263.15 \mathrm{~K}$ to $323.15 \mathrm{~K}$. Solid and dash-dot lines are modeling results from the CPA and SPC-SAFT EOS, respectively. The parameter set \#2 is used for the SPC-SAFT EOS. 


\section{Conclusion}

In this work, a systematic and fair comparison has been conducted for the CPA and sPC-SAFT EOS by applying them into modeling the fluid phase equilibria of gas hydrate related systems. The results show that these two models perform quite similarly in both correlating binary mixtures and predicting multicomponent multiphase equilibria, and the modeling results are satisfactory in most cases. Experimental data are ultimate criteria in process and product design, and they are also necessary for obtaining model parameters and validating model's performance. We show in this work that thermodynamic models can in reverse help in suggesting experimental measurements. For example, more measurements are needed for ethane-water system under high pressures, for methanol-n-hexane LLE data at low concentration of methanol, for water-methanol-n-hexane LLE data and for water-MEG-methane-toluene at low temperatures.

\section{Author Information}

Corresponding Author

* Tel.: 045-45252859. Fax: 045-45882258. Email: gk@kt.dtu.dk

\section{List of Symbols}

EOS = Equation(s) of State

$\mathrm{CPA}=$ Cubic Plus Association

SAFT $=$ Statistical Associating Fluid Theory

PC-SAFT $=$ Perturbed-Chain Statistical Associating Fluid Theory

sPC-SAFT $=$ Simplified Perturbed-Chain Statistical Associating Fluid Theory

$\% \mathrm{AAD}=$ Percent Average Absolute Deviation

$\mathrm{T}=$ Temperature

$\mathrm{P}=$ Pressure 
$V_{m}=$ Molar volume

$\mathrm{R}=$ Ideal Gas constant

$\operatorname{Tr}=$ Reduced temperature (T/critical temperature $)$

$\mathrm{a}^{\mathrm{r}}=$ Reduced residual Helmholtz free energy

$\mathrm{a}^{\mathrm{HS}}=$ Reduced residual Helmholtz free energy from hard-sphere

$\mathrm{a}^{\mathrm{HC}}=$ Reduced residual Helmholtz free energy from chain formation

$\mathrm{a}^{\text {disp }}=$ Reduced residual Helmholtz free energy from dispersion

$\mathrm{a}^{\text {assoc }}=$ Reduced residual Helmholtz free energy from association (hydrogen-bonding)

$b=$ The co-volume parameter

$a(T)=$ The van der Waals energy parameter

$\mathrm{g}=$ Radial distribution function

$\mathrm{m}=$ Segment number

$x_{i}=$ Molar fraction of component $i$

$A_{i}=$ Association site type A of component $i$

$\mathrm{X}^{\mathrm{A}_{\mathrm{i}}}=$ Free site fraction of molecules $i$ not bonded at site $\mathrm{A}$

\section{Greeks Letters}

$\rho=$ Molar density

$\sigma=$ Segment diameter $(\mathrm{T}$ independent $)$

$\varepsilon=$ Segment energy

$\Delta^{\mathrm{A}_{\mathrm{i}} \mathrm{B}_{\mathrm{j}}}=$ Association strength

$\varepsilon^{A_{i} B_{j}}=$ Association energy between sites $A_{i}$ and $B_{j}$

$\kappa^{\mathrm{A}_{\mathrm{i}} \mathrm{B}_{\mathrm{j}}}=$ Association volume between sites $A_{i}$ and $B_{j}$

$\kappa^{\text {cross }}=$ Adjustable cross association volume 


\section{Reference}

(1) Mokbel, I.; Lindemann, C.; Duchet-Suchaux, P.; Jose, J. Liquid-liquid equilibria of binary and ternary systems involving monoethyleneglycol, water, n-alkanes at three temperatures: 283.15, 303.15 and 333.15K. Fuel. 2016, 163, 17-24.

(2) Hydrates. http://petrowiki.org/Hydrates (accessed March 21, 2017).

(3) Jonassen, A. H. Distribution of hydrate inhibitors in processing of gas-condensate. NTNUTrondheim, Norway. 2013.

(4) Kontogeorgis, G. M.; Voutsas, E. C.; Yakoumis, I. V.; Tassios, D. P. An equation of state for associating fluids. Ind. Chem. Eng. Res. 1996, 35, 4310-4318.

(5) Kontogeorgis, G. M.; Folas, G. K. Thermodynamic models for industrial applications - from classical and advanced mixing rules to association theories. John Wiley and Sons: New York, 2010.

(6) Riaz, M. Distribution of Complex Chemicals in Oil-Water Systems. PhD Thesis, Technical University of Denmark, Kgs. Lyngby, Denmark, 2011.

(7) Frost, M. Measurement and Modelling of Phase Equilibrium of Oil-Water-Polar Chemicals. PhD Thesis, Technical University of Denmark, Kgs. Lyngby, Denmark, 2014.

(8) Wertheim, M. S. Fluids with highly directional attractive forces. I. Statistical thermodynamics. J. Stat. Phys. 1984, 35, 19-34.

( 9 ) Wertheim, M. S. Fluids with highly directional attractive forces. II. Thermodynamic perturbation theory and integral equations. J. Stat. Phys. 1984, 35, 35-47.

(10) Wertheim, M. S. Fluids with highly directional attractive forces. III. Multiple attraction sites. $J$. Stat. Phys.1986, 42, 459-476.

( 11 ) Wertheim, M. S. Fluids with highly directional attractive forces. IV. Equilibrium polymerization. J. Stat. Phys. 1986, 42, 477-492.

(12) Chapman, W. G.; Gubbins, K. E.; Jackson, G.; Radosz, M. SAFT: Equation-of-state solution model for associating fluids. Fluid Phase Equilib. 1989, 52, 31-38.

(13) Chapman, W. G.; Gubbins, K. E.; Jackson, G.; Radosz, M. New reference equation of state for associating liquids. Ind. Eng. Chem. Res. 1990, 29, 1709-1721.

(14) Gross, J.; Sadowski, G. Perturbed-chain SAFT: an equation of state based on a perturbation theory for chain molecules. Ind. Eng. Chem. Res. 2001, 40, 1244-1260.

(15) Gross, J.; Sadowski, G. Application of the perturbed-chain SAFT equation of state to associating systems. Ind. Eng. Chem. Res. 2002, 41, 5510-5515.

( 16 ) von Solms, N.; Michelsen, M. L.; Kontogeorgis, G. M. Computational and physical performance of a modified PC-SAFT equation of state for highly asymmetric and associating mixtures. Ind. Eng. Chem. Res. 2003, 42, 1098-1105.

(17) Galindo, A.; Whitehead, P. J.; Jackson, G.; Burgess, A. N. Predicting the high-pressure phase equilibria of water $+n$-alkanes using a simplified SAFT theory with transferable intermolecular interaction parameters. J. Phys. Chem. 1996, 100, 6781-6792.

(18) Voutsas, E. C.; Boulougouris, G. C.; Economou, I. G.; Tassios, D. P. Water/hydrocarbon phase equilibria using the thermodynamic perturbation theory. Ind. Eng. Chem. Res. 2000, 39, 797-804.

(19) Vega, L. F.; Llovell, F.; Blas, F. J. Capturing the solubility minima of n-alkanes in water by soft-SAFT. J. Phys. Chem. B, 2009, 113, 7621-7630.

(20) Dufal, S.; Galindo, A.; Jackson, G.; Haslam, A. J. Modelling the effect of methanol, glycol inhibitors and electrolytes on the equilibrium stability of hydrates with the SAFT-VR approach. Mol. Phys. 2012, 110, 1223-1240. 
(21) Papaioannou, V.; Calado, F.; Lafitte, T.; Dufal, S.; Sadeqzadeh, M.; Jackson, G.; Adjiman, C. S.; Galindo, A. Application of the SAFT- $\gamma$ Mie group contribution equation of state to fluids of relevance to the oil and gas industry. Fluid Phase Equilib. 2016, 416, 104-119.

(22) Ahmed, S.; Ferrando, N.; de Hemptinne, J. C.; Simonin, J. P. Bernard, O.; Baudouin, O. A new PC-SAFT model for pure water, water-hydrocarbons, and water-oxygenates systems and subsequent modeling of VLE, VLLE, and LLE. J. Chem. Eng. Data, 2016, 61, 4178-4190.

(23) Tybjerg, P. C. V.; Kontogeorgis, G. M.; Michelsen, M. L.; Stenby, E. H. Phase equilibria modeling of methanol-containing systems with the CPA and SPC-SAFT equations of state. Fluid Phase Equilib. 2010, 288, 128-138.

(24) Barker, J. A.; Henderson, D. Perturbation theory and equation of state for fluids: the squarewell potential. J. Chem. Phys. 1967, 47, 2856-2861.

(25) Frost, M.; Karakatsani, E.; von Solms, N.; Richon, D.; Kontogeorgis, G. M. Vapor-liquid equilibrium of methane with water and methanol. Measurements and modeling. J. Chem. Eng. Data. 2014, 59, 961-967.

(26) Kiepe, J.; Horstmann, S.; Fischer K.; Gmehling, J. Experimental determination and prediction of gas solubility data for methane + water solutions containing different monovalent electrolytes. Ind. Eng. Chem. Res. 2003, 42, 5392-5398.

(27) Lekvam, K.; Bishnoi, P. R. Dissolution of methane in water at low temperatures and intermediate pressures. Fluid Phase Equilib. 1997, 131, 297-309.

(28) Wang, L. K.; Chen, G. J.; Han, G. H.; Guo, X. Q.; Guo, T. M. Experimental study on the solubility of natural gas components in water with or without hydrate inhibitor. Fluid Phase Equilib. 2003, 207, 143-154.

(29) Gao, J.; Zheng, D. Q.; Guo, T. M. Solubilities of methane, nitrogen, carbon dioxide, and a natural gas mixture in aqueous sodium bicarbonate solutions under high pressure and elevated temperature. J. Chem. Eng. Data. 1997, 42, 69-73.

(30) Culberson, O. L.; McKetta Jr., J. J. Phase equilibria in hydrocarbon-water systems III - The solubility of methane in water at pressures to 10,000 PSIA. Petro. Trans. AIME. 1951, 192, 223226.

(31) Tabasinejad, F.; Gordon Moore, R.; Mehta, S. A.; Van Fraassen, K. C.; Barzin, Y. Water solubility in supercritical methane, nitrogen, and carbon dioxide: measurement and modeling from 422 to $483 \mathrm{~K}$ and pressures from 3.6 to $134 \mathrm{MPa}$. Ind. Eng. Chem. Res. 2011, 50, 4029-4041.

(32) Hong, J. H.; Malone, P. V.; Jett, M. D.; Kobayashi, R. The measurement and interpretation of the fluid-phase equilibria of a normal fluid in a hydrogen bonding solvent: the methane-methanol system. Fluid Phase Equilib. 1987, 38, 83-96.

(33) Yarym-Agaev, N. L.; Sinyavskaya, R. P.; Koliushko, I. I. Phase equilibrium in the binary systems water-methane and methanol-methane under high pressure. Zh. Prikl. Khim. 1985, 58, 165168.

(34) Francesconi, A. Z.; Lentz, H.; Franck, E. U. Phase equilibriums and PVT data for the methanemethanol system to $300 \mathrm{MPa}$ and $240{ }^{\circ} \mathrm{C}$. J. Phys. Chem. 1981, 85, 3303-3307.

(35) Hong, J. H.; Malone, P. V.; Jett, M. D.; Kobayashi, R. The measurement and interpretation of the fluid-phase equilibria of a normal fluid in a hydrogen bonding solvent: the methane-methanol system. Fluid Phase Equilib. 1987, 38, 83-96.

(36) Suzuki, K.; Sue, H.; Itou, M.; Smith, R. L.; Inomata, H.; Arai, K.; Saito, S. Isothermal vaporliquid equilibrium data for binary systems at high pressures: carbon dioxide-methanol, carbon dioxide-ethanol, carbon dioxide-1-propanol, methane-ethanol, methane-1-propanol, ethane-ethanol, and ethane-1-propanol systems. J. Chem. Eng. Data. 1990, 35, 63-66. 
(37) Frolich P. K.; Tauch E. J.; Hogan J. J.; Peer A. A. Solubilities of gases in liquids at high pressure. Ind. Eng. Chem. 1931, 23, 548-550.

(38) Brunner, E.; Hültenschmidt, W. Fluid mixtures at high pressures VIII. Isothermal phase equilibria in the binary mixtures: (ethanol+hydrogen or methane or ethane). J. Chem. Thermodynamics. 1990, 22, 73-84.

(39) Jou, F. Y.; Otto, F. D.; Mather, A. E. Solubility of methane in glycols at elevated pressures. Can. J. Chem. Eng. 1994, 72, 130-133

(40) Zheng, D. Q.; Ma, W.D.; Wei, R.; Guo, T. M. Solubility study of methane, carbon dioxide and nitrogen in ethylene glycol at elevated temperatures and pressures. Fluid Phase Equilib. 1999, 155, $277-286$.

(41) Culberson, O. L.; McKetta Jr., J. J. Phase equilibria in hydrocarbon-water systems II - The solubility of ethane in water at pressures to 10,000 psi. Petro. Trans. AIME. 1950, 189, 319-322.

(42) Mohammadi, A. H.; Chapoy, A.; Tohidi, B.; Richon, D. Measurements and thermodynamic modeling of vapor-liquid equilibria in ethane-water systems from 274.26 to $343.08 \mathrm{~K}$. Ind. Eng. Chem. Res. 2004, 43, 5418-5424.

(43) King Jr., A. D.; Coan, C. R. Solubility of water in compressed carbon dioxide, nitrous oxide, and ethane. Evidence for hydration of carbon dioxide and nitrous oxide in the gas phase. J. Am. Chem. Soc. 1971, 93, 1857-1862.

(44) Chapoy, A.; Coquelet, C.; Richon, D. Measurement of the water solubility in the gas phase of the ethane + water binary system near hydrate formatting conditions. J. Chem. Eng. Data, 2003, 48, 957-966.

(45) Ohgaki, K.; Sano, F.; Katayama, T. Isothermal vapor-liquid equilibrium data for binary systems containing ethane at high pressures. J. Chem. Eng. Data, 1976, 21, $55-58$.

(46) Barrufet, M. A.; Liu, K.; Rahman, S.; Wu, C. Simultaneous vapor-liquid-liquid equilibria and phase molar densities of a quaternary system of propane + pentane + octane + water, J. Chem. Eng. Data. 1996, 41, 918-922.

(47) Tsonopoulos, C.; Wilson, G. M. High-temperature mutual solubilities of hydrocarbons and water. Part I. Benzene, cyclohexane and n-hexane. AIChE J. 1983, 29, 990.

( 48 ) Vapor-liquid equilibrium data of hexane + methanol from Dortmund data bank. http://www.ddbst.com/en/EED/VLE/VLE\%20Hexane\%3BMethanol.php (accessed March 12, 2017).

(49) Ferguson J. B. The system methyl alcohol-n-hexane at 45 degrees. J. Phys. Chem. 1932, 36, 1123-1128.

( 50 ) Góral, M.; Oracz, P.; Warycha, S. Vapour-liquid equilibria XIV. The ternary system cyclohexane-methanol-hexane at 293.15K. Fluid Phase Equilib. 2000, 169, 85-99.

(51) Hradetzky, G.; Lempe, D. A. Phase equilibria in binary and higher systems methanol + hydrocarbons(s): Part I. Experimental determination of liquid-liquid equilibrium data and their representation using the NRTL equation. Fluid Phase Equilib. 1991, 69, 285-301.

(52) Blanco, A. M.; Ortega, J. Experimental study of miscibility, density and isobaric vapor-liquid equilibrium values for mixtures of methanol in hydrocarbons (C5, C6). Fluid Phase Equilib. 1996, 122, 207-222.

(53) Matsuda, H.; Kurihara, K.; Ochi, K.; Kojima, K. Prediction of liquid-liquid equilibria at high pressure for binary systems using EOS-GE models: methanol+hydrocarbon systems. Fluid Phase Equilib. 2002, 203, 269-284. 
(54) Hölscher, I. F.; Schneider, G. M.; Ott, J. B. Liquid-liquid phase equilibria of binary mixtures of methanol with hexane, nonane and decane at pressures up to 160 MPA. Fluid Phase Equilib. 1986, 27, 153-169.

(55) Sinor, J. E.; Weber J. H. Vapor-liquid equilibria at atmospheric pressure. Systems containing ethyl alcohol, n-hexane, benzene and methylcyclopentane. J. Chem. Eng. Data, 1960, 5, 243-247.

(56) Yuan, K. S.; Ho, J. C. K.; Koshpande, A. K.; Lu, B. C. Y. Vapor-liquid equilibria. J. Chem. Eng. Data, 1963, 8, 549-559.

(57) Derawi, S. O.; Kontogeorgis, G. M.; Stenby, E. H.; Haugum, T.; Fredheim, A. O. Liquid-liquid equilibria for glycol hydrocarbons data and correlation. J. Chem. Eng. Data. 2002, 47, 169-173.

(58) Shaw, D.G.; Maczynski, A.; Goral, M.; Wisniewska-Goclowska, B.; Skrzecz, A.; Owczarek, I.; Blazej, K.; Haulait-Pirson, M.C.; Hefter, G.T.; Kapuku, F.; Maczynska, Z. IUPAC-NIST Solubility Data Series. 81. Hydrocarbons with water and seawater revised and updated. Part 7. C8H12-C8H18 hydrocarbons with water. J. Phys. Chem. Ref. Data. 2005, 34, 2261-2298.

(59) Heidman, J. L.; Tsonopoulos, C.; Brady, C. J.; Wilson, G. M. High-temperature mutual solubilities of hydrocarbons and water II: ethylbenzene, ethylcyclohexane, and n-octane. AIChE J. 1985, 31, 376-384.

(60) Ott, J. B.; Hölscher, I. F.; Schneider, G. M. (Liquid + liquid) phase equilibria in (methanol + heptane) and (methanol + octane) at pressures from 0.1 to $150 \mathrm{MPa}$. J. Chem. Thermodyn. 1986, 18, 815-826.

(61) Higashiuchi, H.; Sakuragi, Y.; Iwai, Y.; Arai, Y.; Nagatani, M. Measurement and Correlation of Liquid-Liquid Equilibria of Binary and Ternary Systems Containing Methanol and Hydrocarbons. Fluid Phase Equilib. 1987, 36, 35-47.

(62) Kurihara, K.; Midorikawa, T.; Hashimoto, T.; Kojima, K.; Ochi, K. Liquid-liquid solubilities for the binary systems of methanol with octane and 2,2,4-trimethylepentane. J. Chem. Eng. Japan, 2002, 35, 360-364.

(63) Boublikova, L.; Lu, B. C. Y. Isothermal vapour-liquid equilibria for the ethanol-n-octane system. J. Chem. Technol. Biotech. 1969, 19, 89-92.

(64) Janaszewski, B.; Oracz, P.; Goral, M.; Warycha, S. Vapour-liquid equilibria. I. An apparatus for isothermal total vapour pressure measurements: binary mixtures of ethanol and t-butanol with nhexane, n-heptane and n-octane at 313.15 K. Fluid Phase Equilib. 1982, 9, 295-310.

( 65 ) Vapor-liquid equilibrium data of benzene + water from Dortmund data bank. http://www.ddbst.com/en/EED/VLE/VLE\%20Benzene\%3BWater.php (accessed March 12, 2017).

(66) Jou, F. Y.; Mather, A. E. Liquid-liquid equilibria for binary mixtures of water + benzene, water + toluene and water + p-xylene from $273 \mathrm{~K}$ to $458 \mathrm{~K}$. J. Chem. Eng. Data. 2003, 48, 750-752.

(67) Scatchard, G.; Ticknor, L. B. Vapor-liquid equilibrium. IX. The methanol-carbon tetrachloridebenzene system. J. Am. Chem. Soc. 1952, 74, 3724-3729.

( 68 ) Vapor-liquid equilibrium data of benzene + methanol from Dortmund data bank. http://www.ddbst.com/en/EED/VLE/VLE\%20Benzene\%3BMethanol.php (accessed March 12, 2017).

(69) Miyano Y.; Hayduk, W. Solubilities of isobutane in methanol + benzene, methanol + cyclohexane and benzene + cyclohexane mixed solvent solutions at $298 \mathrm{~K}$ and 40-102 kPa. Fluid Phase Equilib. 1993, 38, 277-268.

(70) Toghiani, H.; Toghiani, R. K.; Viswanath, D. S. Vapor-liquid equilibria for the methanolbenzene and methanol-thiophene systems. J. Chem. Eng. Data, 1994, 39, 63-67.

(71) Scatchard, G.; Wood, S. E.; Mochel, J. M. Vapor-liquid equilibrium. VI. Benzene-methanol mixtures. J. Am. Chem. Soc. 1946, 68, 1957-1960. 
(72) Nagata, I. Vapor-liquid equilibrium data for the binary systems methanol-benzene and methyl acetate-methanol. J. Chem. Eng. Data. 1969, 14, 418-420.

(73) Brown, I.; Smith, F. Liquid-vapour equilibria. IV. The system ethanol + benzene at $45^{\circ} \mathrm{C}$. Austra. J. Chem. 1954, 7, 264-268.

(74) Zielkiewicz, J.; Oracz, P.; Warycha, S. Total vapour pressure measurements and excess Gibbs energies for the binary systems methanol + ethanol, ethanol + 2-propanol, benzene + cyclohexane, benzene + carbon tetrachloride and benzene + ethanol at 303.15 and 313.15 K. Fluid Phase Equilib. 1990, 58, 191-209.

(75) Udovenko, V. V.; Fatkulina, L. G. Vapor pressure of three-component systems. I. The system ethyl alcohol-1, 2-dichloroethane-benzene. Zh. Fiz. Khim, 1952, 26, 719-730.

(76) Góral, M.; Skrzecz, A.; Bok, A.; Mączyński, A. Recommended vapor-liquid equilibrium data. Part 3. Binary alkanol-aromatic hydrocarbon systems. J. Phys. Chem. Ref. Data, 2004, 33, 959-997.

(77) Folas, G. K.; Kontogeorgis, G. M.; Michelsen, M. L.; Stenby, E. H.; Solbraa, E. Liquid-liquid equilibria for binary and ternary systems containing glycols, aromatic hydrocarbons and water: experimental measurements and modeling with the CPA EoS. J. Chem. Eng. Data. 2006, 51, 977983.

(78) Kretschmer, C. B.; Wiebe, R. Liquid-Vapor Equilibrium of Ethanol - Toluene Solutions. J. Am. Chem. Soc. 1949, 71, 1793-1797.

(79) Van Ness, H. C.; Soczek, C. A.; Peloquin, G. L.; Machado, R. L. Thermodynamic excess properties of three alcohol-hydrocarbon systems. J. Chem. Eng. Data. 1967, 12, 217-224.

(80) Butler, J. A. V.; Thomson, D. W.; Maclennan, W. H. The free energy of the normal aliphatic alcohols in aqueous solution. Part I. The partial vapour pressures of aqueous solutions of methyl, npropyl, and n-butyl alcohols. Part II. The solubilities of some normal aliphatic alcohols in water. Part III. The theory of binary solutions, and its application to aqueous-alcoholic solutions. J. Chem. Soc. 1933, 674-686.

(81) Griswold, J.; Wong, S. Y. Phase equilibria of the acetone-methanol-water systems from $100^{\circ} \mathrm{C}$ into the critical region. Chem. Eng. Prog. Symp. Ser. 1952, 48, 18-34.

(82) Kurihara, K.; Minoura, T.; Takeda, K.; Kojima, K. Isothermal vapor-liquid equilibria for methanol + ethanol + water, methanol + water, and ethanol + water. J. Chem. Eng. Data. 1995, 40, 679-684.

(83) Ratcliff, G. A.; Chao, K. C. Prediction of thermodynamic properties of polar mixtures by a group solution model. Can. J. Chem. Eng. 1969, 47, 148-153.

(84) Chiavone-Filho, O.; Proust, P.; Rasmussen, P. Vapor-liquid equilibria for glycol ether + water systems. J. Chem. Eng. Data. 1993, 38, 128-131.

(85) $\mathrm{Ng}, \mathrm{H}$. J.; Robinson, D. B. Equilibrium phase composition and hydrating conditions in systems containing methanol, light hydrocarbons, carbon dioxide, and hydrogen sulfide. GPA Research Report 66. Gas Processors Association: Tulsa, Okla. 1983.

(86) Noda, K.; Sato, K.; Nagatsuka, K.; Ishida, K. Ternary liquid-liquid equilibria for the systems of aqueous methanol solutions and propane or n-butane. J. Chem. Eng. Japan. 1975, 8, 492-493.

(87) Skrzecz, A.; Shaw, D.; Maczynski, A. IUPAC-NIST Solubility Data Series. 69. Ternary alcohol-hydrocarbon-water systems. J. Phys. Chem. Ref. Data. 1999, 28, 983-1235.

(88) Liu, J.; Qin, Z.; Wang, J. Liquid-liquid equilibria for methanol + water + hexane ternary mixtures. J. Chem. Eng. Data. 2002, 47, 1243-1245.

(89) Lindemann, C.; Duchet-Suchaux, P.; Razzouk, A.; Mokbel, I.; Jose, J. Liquid-liquid equilibria of binary and ternary systems methanol/water + n-hexane, + n-octane, + n-dodecane, and $+n$ - 
hexadecane in the temperature range between $\mathrm{T}=283.15 \mathrm{~K}$ and $\mathrm{T}=333.15 \mathrm{~K}$. J. Chem. Eng. Data. 2016, 61, 2412-2418.

(90) Letcher, T. M.; Wootton, S.; Shuttleworth, B.; Heyward, C. Phase equilibria for (n-heptane+ water+ an alcohol) at 298.2 K. J. Chem. Thermodyn. 1986, 18, 1037-1042.

(91) Triday, J. O. Liquid-liquid equilibria for the system benzene-water-methanol, J. Chem. Eng. Data. 1984, 29, 321-324.

(92) de Doz, M. B. G.; Bonatti, C. M.; Sólimo, H. N. Liquid-liquid equilibria of ternary and quaternary systems with two hydrocarbons, an alcohol, and water at $303.15 \mathrm{~K}$ System containing 2,2,4-trimethylpentane, toluene, methanol, and water, or 2,2,4-trimethylpentane, toluene, ethanol, and water. Fluid Phase Equilib. 2003, 205, 53-67.

(93) Razzouk, A.; Naccoul, R. A.; Mokbel, I.; Duchet-Suchaux, P.; Jose, J.; Rauzy, E.; Berro, C. Liquid-Liquid Equilibria for Monoethylene Glycol + Hexane and 2,2,4-Trimethylpentane, Water + Hexane and 2,2,4-Trimethylpentane, Monoethylene Glycol + Water + Hexane, and Monoethylene Glycol + Water $+2,2,4$-Trimethylpentane in the Temperature Range between $\mathrm{T}=283.15 \mathrm{~K}$ and $\mathrm{T}=$ 323.15 K. J. Chem. Eng. Data. 2010, 55, 1468-1472.

( 94 ) Riaz, M.; Yussuf, M. A.; Kontogeorgis, G. M.; Stenby, E. H.; Yan, W.; Solbraa, E. Distribution of MEG and methnaol in well-defined hydrocarbon and water systems: Experimental measurement and modeling using CPA EoS. Fluid Phase Equilib. 2013, 337. 298-310.

(95) Horizoe, H.; Tanimoto, T.; Yamamoto, I.; Kano, Y. Phase Equilibrium study for the separation of ethanol-water solution using subcritical and supercritical hydrocarbon solvent extraction. Fluid Phase Equilib. 1993, 84, 297-320.

(96) Gomis, V.; Font, A.; Pedraza, R.; Saquete, M. D. Isobaric vapor-liquid and vapor-liquid-liquid equilibrium data for the water-ethanol-hexane system. Fluid Phase Equilib. 2007, 259, 66-70.

(97) Ross, S.; Patterson, R. E. Surface and Interfacial Tensions of Conjugate Solutions in Ternary Systems. J. Chem. Eng. Data. 1979, 24, 111-115.

(98) Brandani, V.; Chianese, A.; Rossi, M. Ternary liquid-liquid equilibrium data for the waterethanol-benzene system. J. Chem. Eng. Data. 1985, 30, 27-29.

(99) Mostafazadeh, A. K.; Rahimpour, M. R.; Shariati, A. Vapor-liquid equilibria of water + triethylene glycol (TEG) and water + TEG + toluene at $85 \mathrm{kPa}$. J. Chem. Eng. Data. 2009, 54, 876881.

(100) Ng, H. J.; Chen, C. J.; Robinson, D. B. Vapour-liquid and vapour-liquid-liquid equilibria for $\mathrm{H} 2 \mathrm{~S}, \mathrm{CO} 2$, Selected light hydrocarbons and a gas condensate in aqueous methanol or ethylene glycol solutions. GPA Research Report 149. Gas Processors Association: Tulsa, Okla. Gas Research Institute: Chicago, IL. 1995.

(101) Chen, C. J.; Ng, H. J.; Robinson, D. B. The solubility of methanol or glycol in waterhydrocarbon systems. GPA Research Report 117. Gas Processors Association: Tulsa, Okla. 1988.

(102) Ng, H. J.; Chen, C. J.; Robinson, D. B. The influence of high concentrations of methanol on hydrate formation and the distribution of glycol in liquid-liquid mixtures. GPA Research Report 106. Gas Processors Association: Tulsa, Okla. 1987.

(103) Ashcroft, S. J.; Brunner, G.; Vollmer, H.; Sweeney, C. W. Three-phase vapor-liquid-liquid equilibria for methane + n-octane + monoethylene glycol + water at pressures from (3.1 to 15.0) MPa and temperatures from (281 to 363) K. J. Chem. Eng. Data. 2009, 54, 1613-1618.

(104) Clark, G. N. I.; Haslam, A. J.; Galindo, A.; Jackson, G. Developing optimal Wertheim-like models of water for use in Statistical Associating Fluid Theory (SAFT) and related approaches. Mol. Phys. 2006, 104, 3561-3581. 
(105) Grenner, A.; Kontogeorgis, G. M.; Michelsen, M. L.; Folas, G. K. On the estimation of water pure compound parameters in association theories. Mol. Phys. 2007, 105, 1797-1801.

(106) Liang, X. D.; Tsivintzelis, I.; Kontogeorgis, G. M. Modeling water containing systems with the simplified PC-SAFT and CPA equations of state. Ind. Eng. Chem. Res. 2014, 53, 14493-14507.

(107) Liang, X. D. Thermodynamic modeling of complex systems. PhD Thesis, Technical University of Denmark, Kgs. Lyngby, Denmark, 2014.

(108) Huang, S. H.; Radosz, M. Equation of state for small, large, polydisperse, and associating molecules. Ind. Eng. Chem. Res. 1990, 29, 2283-2294.

(109) Fouad, W. A.; Wang, L.; Haghmoradi, A.; Asthagiri, D.; Chapman, W. G. Understanding the thermodynamics of hydrogen bonding in alcohol-containing mixtures: cross-association. J. Phys. Chem. B, 2016, 120, 3388-3402.

(110) DIPPR Database, Design Institute for Physical Property Data; DIADEM, Information and Data Evaluation Manager, version 6.0.1, 2012.

(111) REFPROP, Reference Fluid Thermodynamic and Transport Properties, NIST Standard Reference Database 23, Version 9.0, 2010.

(112) NIST Chemistry WebBook. http://webbook.nist.gov/chemistry/ (accessed March 14, 2017).

(113) Tsivintzelis, I.; Kontogeorgis, G. M.; Michelsen, M. L.; Stenby, E. H. Modeling phase equilibria for acid gas mixtures using the CPA equation of state. I. Mixtures with $\mathrm{H}_{2} \mathrm{~S}$. AIChE J. 2010, 56, 2965-2982.

( 114 ) Kontogeorgis, G. M.; Yakoumis, I. V.; Meijer, H.; Hendriks, E.; Moorwood, T. Multicomponent phase equilibrium calculations for water-methanol-alkane mixtures. Fluid Phase Equilib. 1999, 158-160, 201-209.

(115) Yakoumis, I. V.; Kontogeorgis, G. M.; Voutsas, E. C.; Tassios, D. P. Vapor-liquid equilibria for alcoholhydrocarbon systems using the CPA equation of state. Fluid Phase Equilib. 1997, 130, 31-47.

(116) Derawi, S. O.; Michelsen, M. L.; Kontogeorgis, G. M.; Stenby, E. H. Application of the CPA equation of state to glycol/hydrocarbons liquid-liquid equilibria. Fluid Phase Equilib. 2003, 209, 163-184.

(117) Liang, X. D.; Maribo-Mogensen, B.; Thomsen, K.; Yan, W.; Kontogeorgis, G. M. Approach to improve speed of sound calculation within PC-SAFT framework. Ind. Eng. Chem. Res. 2012, 51, 14903-14914.

(118) Tsivintzelis, I.; Grenner, A.; Economou, I. G.; Kontogeorgis, G. M. Evaluation of the nonrandom hydrogen bonding (NRHB) theory and the simplified perturbed-chain - statistical associating fluid theory (sPC-SAFT). 2. Liquid-liquid equilibria and prediction of monomer fraction in hydrogen bonding systems. Ind. Eng. Chem. Res. 2008, 47, 5651-5659.

(119) Liang, X. D.; Thomsen, K.; Yan, W.; Kontogeorgis, G. M. Modeling the liquid-liquid equilibrium of petroleum fluid and polar compounds containing systems with the PC-SAFT equation of state. Fluid Phase Equilib. 2015, 406, 147-155.

(120) Grenner, A.; Kontogeorgis, G. M.; von Solms, N.; Michelsen, M. L. Modeling phase equilibria of alkanols with the simplified PC-SAFT equations of state and generalized pure compoud parameters. Fluid Phase equilib. 2007, 258, 83-94. 
For Table of Contents Only

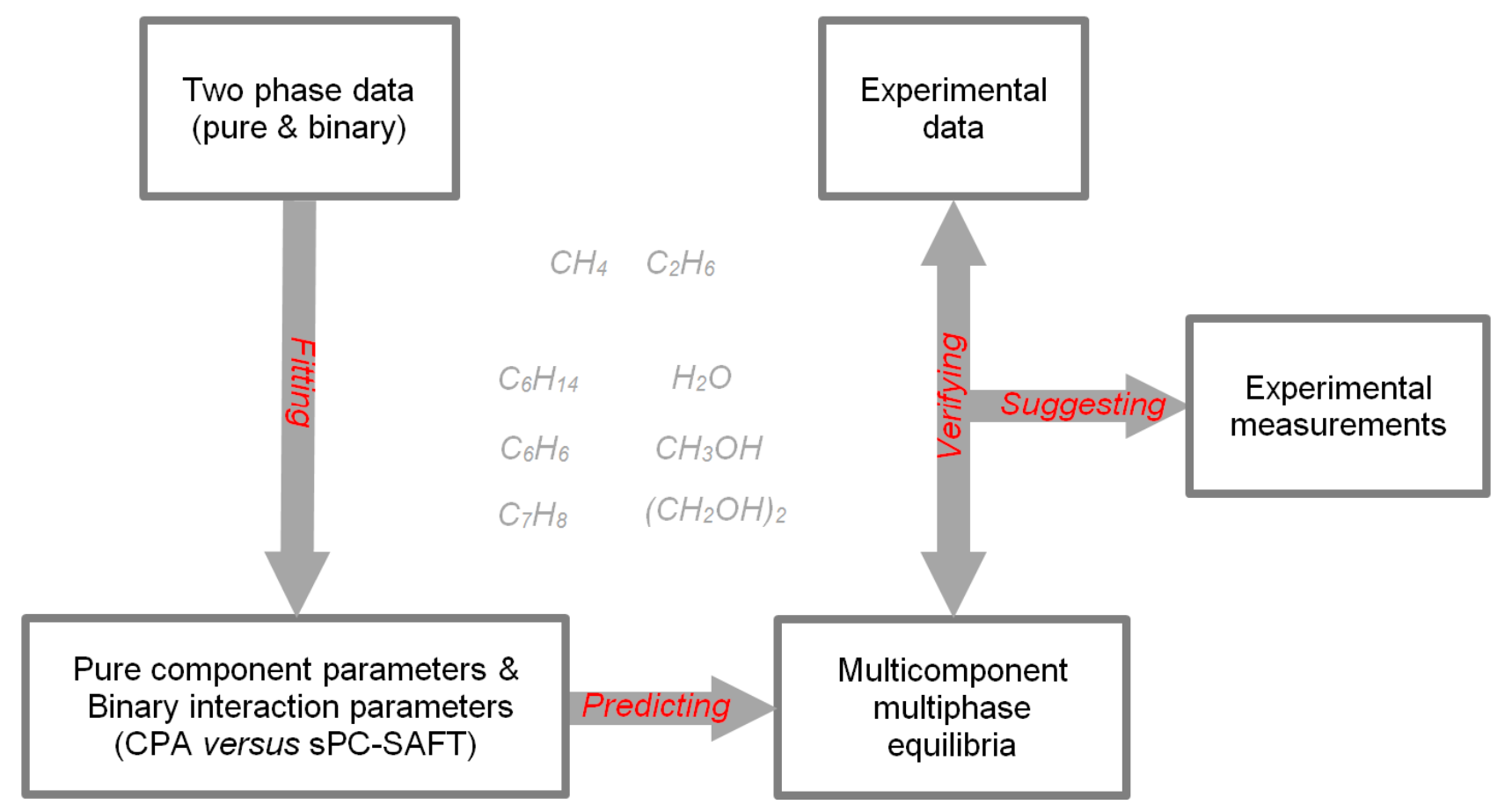

